Article

\title{
Evaluation of the Factors Impacting the Water Pipe Leak Detection Ability of GPR, Infrared Cameras, and Spectrometers under Controlled Conditions
}

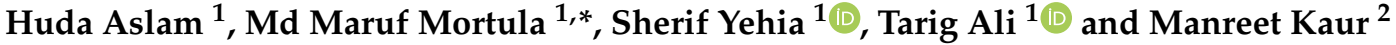 \\ 1 Department of Civil Engineering, American University of Sharjah, Sharjah P.O. Box 26666, United Arab Emirates; \\ g00052579@alumni.aus.edu (H.A.); syehia@aus.edu (S.Y.); atarig@aus.edu (T.A.) \\ 2 Whitby and Mohajer Engineering Consultants, Block A, Emarat Atrium Building, Sheikh Zayed Road, \\ Dubai P.O. Box 26739, United Arab Emirates; m.kaur@wmeglobal.com \\ * Correspondence: mmortula@aus.edu
}

Citation: Aslam, H.; Mortula, M.M.; Yehia, S.; Ali, T.; Kaur, M. Evaluation of the Factors Impacting the Water Pipe Leak Detection Ability of GPR, Infrared Cameras, and Spectrometers under Controlled Conditions. Appl. Sci. 2022, 12, 1683. https://doi.org/ 10.3390/app12031683

Academic Editor: Bruno Brunone

Received: 31 December 2021

Accepted: 2 February 2022

Published: 6 February 2022

Publisher's Note: MDPI stays neutral with regard to jurisdictional claims in published maps and institutional affiliations.

Copyright: (C) 2022 by the authors. Licensee MDPI, Basel, Switzerland. This article is an open access article distributed under the terms and conditions of the Creative Commons Attribution (CC BY) license (https:// creativecommons.org/licenses/by/ $4.0 /)$.

\begin{abstract}
Leakages from water distribution infrastructures are responsible for a considerable amount of water losses. Consequently, innovative, non-destructive techniques (NDT) of leakage detection for early recognition is vital. In this study, the leak detection abilities of Ground Penetration Radar (GPR), spectrometers, and infrared (IR) cameras were investigated, and the factors affecting the leak detection response were assessed. Three experimental setups were constructed to simulate underground pipes in dune sand. Three different pipe materials (PVC, PPR, and PE) were investigated under three levels of moisture content (MC; $2 \%, 5 \%$, and $10 \%$ ) and three types of leaks (hole, crack, and faulty joint). The IR camera was the most effective among the different NDTs used in this study. The IR camera detected all types of leaks at $2 \%$ and $5 \% \mathrm{MC}$ but was inconclusive at $10 \% \mathrm{MC}$. Similarly, the GPR detected the leaks at $\%$ and 5\% MC successfully but was inconclusive at $10 \% \mathrm{MC}$. Lastly, the spectrometer was the least reliable NDT to detect leaks. Results suggest that IR cameras and spectrometers that operate in the mid-IR range $(5-25 \mu \mathrm{m})$ can detect leaks.
\end{abstract}

Keywords: non-destructive testing; water leak detection; ground penetrating radar; infrared thermography; spectrometry

\section{Introduction}

Water plays a vital role in our lives and is used for domestic, agricultural, commercial, industrial, and recreational purposes. The inexorable growth in the population, depletion in the freshwater resources due to climate changes, and overutilization has led to water scarcity. Studies suggest that leaks in Water Distribution Infrastructure (WDI) can cause water losses of up to $30 \%$ [1,2]. For example, in UAE, the Dubai Electricity and Water Authority estimated the water losses in the WDI as $8.2 \%$ of the total water in the network [3]. Water pipe leakage not only leads to wastage of a precious resource but it also causes significant financial losses as a large amount of treated water is lost through leaks. In addition, water leaking can damage surrounding pipes, foundations of buildings, and underground utility cables [4]. Moreover, water in the infrastructure could potentially be infected by contaminants which enter through damages in pipes [5]. Clean drinking water and environmental degradation fighting are two worldwide challenges addressed by the Sustainable Development Goals [6]. To deal with these two challenges also implies reducing water leakage as it causes wasting of drinking water and risks the water quality. Consequently, it is imperative to develop an efficient approach for the detection of leaks in water distribution infrastructure to reduce the negative effects associated with water pipe leaks. 


\subsection{Leak Detection Methods}

Many methods for detecting leaks in water distribution infrastructure have emerged. Leak detection methods can be categorized as destructive (DT) and non-destructive techniques (NDT). Destructive techniques alter the chemical composition or the dimensional geometry of the material under testing. The external installation of hardware devices on water pipelines, which requires excavation of the soil above the pipes, is an example of DTs. Due to the complexity of DTs, NDTs are widely preferred because they provide an opportunity to evaluate the properties and condition of the materials, i.e., water pipes, without changing the structure of the water distribution infrastructure, without excavating the soil above the water pipes, or without disrupting the serviceability of the system. Several NDTs have proven their ability to detect leaks in water infrastructure. Table 1 summarizes some of the NDTs often used for water leak detection.

Table 1. Non-destructive techniques adapted from Liu and Kleiner [7].

\begin{tabular}{|c|c|c|c|}
\hline Method & Objective & Advantage & Disadvantage \\
\hline \multicolumn{4}{|c|}{ Visual Inspection } \\
\hline $\begin{array}{l}\text { Closed-circuit television } \\
\text { (CCTV) }\end{array}$ & $\begin{array}{c}\text { Inspects the inner surface of the } \\
\text { pipe. }\end{array}$ & $\begin{array}{l}\text { a. Applied to sewer and storm } \\
\text { water pipes } \\
\text { b. Used for water main } \\
\text { rehabilitation }\end{array}$ & $\begin{array}{l}\text { a. Requires a pan and a tilt. } \\
\text { b. The carrier speed of the } \\
\text { CCTV camera is limited to } \\
15 \mathrm{~cm} / \mathrm{s} \text {. }\end{array}$ \\
\hline Laser scan & $\begin{array}{l}\text { Measures the inner pipe distance } \\
\text { by laser. }\end{array}$ & $\begin{array}{l}\text { a. Used for relatively longer } \\
\text { distance measurements in the } \\
\text { interior of the pipes } \\
\text { b. Creates high resolution } \\
\text { surface profiles of the pipes }\end{array}$ & $\begin{array}{l}\text { a. Can only be used in } \\
\text { dewatered pipes. } \\
\text { b. Requires data processing. }\end{array}$ \\
\hline
\end{tabular}

Electromagnetic Methods

\begin{tabular}{|c|c|c|c|c|}
\hline $\begin{array}{l}\text { Ultra-wideband }(\mathrm{UWB}) \text { pulsed } \\
\text { radar system: } \mathrm{P} \text {-scan }\end{array}$ & $\begin{array}{l}\text { Inspects the condition of the pipe } \\
\text { by transmitting and receiving } \\
\text { electromagnetic pulses in the } \\
\text { nano and pico-second ranges. }\end{array}$ & a. & $\begin{array}{l}\text { Potential for pipe condition } \\
\text { assessment } \\
\text { High resolution due to use of } \\
\text { ultra-short duration pulses }\end{array}$ & $\begin{array}{l}\text { Pre-commercial prototype of this } \\
\text { system is still under development. }\end{array}$ \\
\hline \multicolumn{5}{|c|}{ Acoustic Methods } \\
\hline Sonar profiling system & $\begin{array}{c}\text { Inspects precise pipe } \\
\text { cross-sections and potential } \\
\text { leakages. }\end{array}$ & a. & $\begin{array}{l}\text { Accurate measurements are } \\
\text { attained } \\
\text { Provides high resolution }\end{array}$ & $\begin{array}{ll}\text { a. High-frequency sonar has } \\
\text { low penetration capability } \\
\text { b. Low-frequency sonar has } \\
\text { low revolution scan. }\end{array}$ \\
\hline Impact echo & $\begin{array}{l}\text { Inspects pipe thickness based on } \\
\text { the use of impact-generated stress } \\
\text { waves. }\end{array}$ & $\begin{array}{l}\text { a. } \\
\text { b. }\end{array}$ & $\begin{array}{l}\text { Applied to materials such as } \\
\text { concrete, stone, plastic, } \\
\text { masonry materials, wood, } \\
\text { and some ceramics } \\
\text { Not limited by pipe size }\end{array}$ & $\begin{array}{l}\text { a. Frequency domain analysis } \\
\text { is complicated. } \\
\text { b. Embedded items may affect } \\
\text { wave behavior and test } \\
\text { results. }\end{array}$ \\
\hline \multicolumn{5}{|c|}{ Ultrasound Methods } \\
\hline Guided wave ultrasound & $\begin{array}{l}\text { Inspects pipe cross-sections based } \\
\text { on propagating a wave for a long } \\
\text { distance. }\end{array}$ & Use & $\begin{array}{l}\text { to characterize metal loss due } \\
\text { to the corrosion }\end{array}$ & $\begin{array}{l}\text { a. Only suitable for pipes } \\
\text { above } 5 \mathrm{~cm} \text { in diameter and } \\
\text { with wall thicknesses of up } \\
\text { to } 4 \mathrm{~cm} \text {. }\end{array}$ \\
\hline
\end{tabular}

Most methods are limited in their ability to apply the technologies consistently in wide-ranging environmental circumstances. In addition, there are technologies that are complicated for field applications and some of them are also unproven. Due to the limitations of the currently used leak detection methods, robust methods, which can be easily implemented, are efficient, and are reliable, are being investigated. The following three NDTs were chosen for further study: Ground Penetrating Radar (GPR), a hand-held spectrometer, and an infrared (IR) camera. This study also investigated the versatility of these technologies in wide-ranging environmental conditions.

Transient Test-Based Techniques (TTBTs) identify leaks and other possible faults (e.g., partial blockages and pipe wall deteriorations) straightforwardly on the basis of 
the measured reflected pressure waves [8,9]. It is worth noting that with respect to other techniques, TTBTs are very attractive since the duration of the test is very short and they allow for detecting also devious defects (e.g., partial blockages and illegal branches) which do not give rise to any exterior sign. Moreover, small but sharp amplitude pressure waves allow for reliable fault detection [10].

\subsection{Ground Penetrating Radar (GPR)}

Ground Penetrating Radar (GPR) is a non-invasive, high-resolution geophysical method where antennas may be up to a few $\mathrm{GHz}$ to produce an image of the subsurface conditions [11]. It has a wide range of applications in the field of civil engineering, such as the mapping of soil layers, detection of buried services, inspection of pavement layers, inspection and quality control of concrete structures, etc. Ayala-Cabrera et al. [12] discussed that using parallel profiles can help identify significant differences between the profiles. It was also possible to construct stages of the leak and water dissipation through the soil. Additionally, Wallace et al. [13] devoted their research efforts to collect signature images to a water leak, utilizing differences of the dielectric contrast and reflection coefficient at various water injection stages. These images are used to identify water leaks in pressurized water supply pipes or drainage pipes. Another study by De Coster et al. [14] focused on using advanced, integrated radar data processing and visualization strategies. They used full-wave inversion to estimate the medium properties, in addition to the removal of near-field antenna effects as well as reflection detection and segmentation algorithms. They also highlighted the importance of 3D images and qualitative data processing strategies that help in detecting continuous objects (pipes) from buried stones. A review by Zajícová and Chuman [15] highlighted that 3D image models are used to provide details about the soil layers, thickness, and volume calculations. However, one of the disadvantages is the time and data acquisition required to build these models. In addition, there have been many experiments conducted on the use of the GPR to detect leaks in water pipes buried underground, as summarized in Table 2.

Table 2. Studies using GPR for water leak detection.

\begin{tabular}{|c|c|c|c|c|c|}
\hline Study Type & Soil & Pipe Material & Pipe Diameter (mm) & Results & Reference \\
\hline $\mathrm{Lab}$ & Dry soil & PVC & 100 & $\begin{array}{l}\text { GPR was successful in not only detecting the } \\
\text { leak but also reconstructing the various stages } \\
\text { of the leak and how water dissipated through } \\
\text { the soil }\end{array}$ & [12] \\
\hline Field & $\begin{array}{l}\text { Gravel, sand, silt, } \\
\text { and clay }\end{array}$ & Unknown & - & $\begin{array}{l}\text { GPR produced inferior results as the presence } \\
\text { of clay resulted in absorption of the GPR } \\
\text { signals }\end{array}$ & [16] \\
\hline Field & Unknown & Unknown & - & $\begin{array}{l}\text { GPR can be applicable for leak detection of } \\
\text { several types of pipes }\end{array}$ & [17] \\
\hline $\mathrm{Lab}$ & Sand & Metal and PVC & 19 & $\begin{array}{l}\text { Raw data collected in the field by GPR is } \\
\text { sufficient to detect water leaks }\end{array}$ & [18] \\
\hline Lab and field & Dry soil & $\begin{array}{l}\text { Lab: PVC, Field: } \\
\text { cast iron }\end{array}$ & Lab: 100 Field: 400 & $\begin{array}{l}\text { Difficult to interpret raw images, more } \\
\text { complex models are needed }\end{array}$ & [19] \\
\hline Lab and field & Silt and clay & $\begin{array}{l}\text { Plastic and } \\
\text { metallic }\end{array}$ & - & $\begin{array}{l}\text { GPR technique provided a good estimation of } \\
\text { the position of the leak; however, its response } \\
\text { is influenced by the presence of other buried } \\
\text { objects/anomalies underground }\end{array}$ & [20] \\
\hline Lab and field & Dry sand & Plastic & 50 & $\begin{array}{l}\text { Successful but detection through voids highly } \\
\text { depends on the investigated medium and the } \\
\text { radar system parameters }\end{array}$ & [21] \\
\hline $\mathrm{Lab}$ & Soil & Cement & 200 & GPR was successful in water leak detection & [22] \\
\hline Field & Silty clay & PVC & 152.4 & $\begin{array}{l}\text { The pipe appears slightly deeper in the image } \\
\text { above the leak, which could indicate radar } \\
\text { waves slowed by saturated soil near the leak }\end{array}$ & [23] \\
\hline
\end{tabular}


GPR uses electromagnetic (EM) pulses in the microwave range. The GPR records the strength and time of the return of any reflected signals after sending the energy pulses into the ground. This series of pulses spanning over a single area is called a scan. The signals are reflected when the energy pulses transmitted through various materials hit the object buried underground. This, thus, changes the velocity of signals originated due to contrasts in dielectric properties that are reflected back. The changes in the velocity depend basically on two primary electrical properties of the subsurface: electrical conductivity $(\sigma)$ and relative permittivity $(\varepsilon)$ [24] According to Topp's equation, the water content $(\Theta)$ of the soil impacts the minor magnetic permeability of the soil, as shown in Equation (1) [25].

$$
\mathcal{\varepsilon}_{\text {eff }}=3.03+9.3 \Theta+146 \Theta^{2}-76.7 \Theta^{3},
$$

Hence, it is expected that the change in the moisture content due to the leak will affect the dielectric constant and would, in turn, impact the velocity of signals, thereby, detecting the leak.

\subsection{Spectrometer}

The spectrometer is an optical instrument that measures the spectral responses of different materials. The basic function of a spectrometer is to disperse and measure the electromagnetic energy (mostly solar) reflected or emitted by an object into its spectral components and digitize the signal as a function of wavelength; thus, the physical and chemical properties of the object emitting the light can be inferred by analyzing its spectral components. In the context of this experiment, water pipes and soil provide spectral reflectance. Numerous studies have attempted to predict various soil properties, such as soil moisture content, texture, salinity, organic content, etc., by analyzing its spectral reflectance. A leak in a water infrastructure leads to an increase in the moisture content of the surrounding soil as the water from the leak penetrates the soil; therefore, the soil moisture content is the soil property of interest when dealing with spectrometers. Table 3 summarizes some of the studies that used spectrometers to identify the soil moisture content. Therefore, although there are no studies conducted on the use of spectrometers for water leak detection, there is a strong reason to believe that this technology has potential as a water leak detection method given its ability to detect changes in the water content within soil layers. Preliminary experimentation was conducted by the authors prior to main testing to determine if spectrometers could detect pipe leaks. The results of the preliminary testing were promising. As the leak time increased, the moisture content of the soil surrounding the leak increased. This resulted in a decreased reflectance of the wavelength, specifically higher than $700 \mathrm{~nm}$ (infrared band) [26-28].

\subsection{Infrared (IR) Camera}

An infrared (IR) camera detects infrared energy reflected or emitted by an object and converts it into a thermal image. A leak in an underground water infrastructure may alter the surface temperature of the surrounding soil because normally leaked water is cooler than the soil, which absorbs heat much faster than water. Table 4 summarizes the studies that investigated the efficiency of IR cameras in detecting thermal contrasts at the soil surface due to water leaks in the buried pipes. Although the efficiency of an IR camera has been determined using the optimum time to use the camera [37], the distance of the camera from the source [37,38], and the rate of capturing images [37], previous studies ignored the efficiency of IR cameras in wide-ranging pipe materials and soils, as well as environmental characteristics (such as different levels of MC). Apart from the IR camera, the thermal leak detection approach was also successful [39]. 
Table 3. Studies using spectrometers for soil moisture content determination.

\begin{tabular}{|c|c|c|c|c|}
\hline Spectrometer & Soil Type & Moisture Content & Results & Reference \\
\hline $\begin{array}{l}\text { Fourier Transform } \\
\text { Infrared Spectrometer }\end{array}$ & $\begin{array}{l}\text { Silt clay loam, loam, clay } \\
\text { loam, and silt clay }\end{array}$ & $4.6-48.5 \%$ & $\begin{array}{l}\text { As the moisture increases, reflectance } \\
\text { from soil decreases and vice versa }\end{array}$ & [29] \\
\hline $\begin{array}{l}\text { Infra-Red Intelligent } \\
\text { Spectroradiometer }\end{array}$ & $\begin{array}{l}\text { Soils from sandstone, basic } \\
\text { rocks, basalt, and shale }\end{array}$ & $420.71 \%$, oven dried & $\begin{array}{l}\text { The increase of moisture contents } \\
\text { promoted a reduction in the magnitude } \\
\text { of spectral reflectance }\end{array}$ & [30] \\
\hline ASD FieldSpec Pro & $\begin{array}{l}\text { Quartz sand, masonry } \\
\text { sand, and Ithaca sand }\end{array}$ & $55.7 \%$, oven dried & $\begin{array}{l}\text { As water content increases, reflectance } \\
\text { decreases at all } \\
\text { wavelengths but the decrease is much } \\
\text { more pronounced in the infrared }\end{array}$ & [31] \\
\hline $\begin{array}{l}\text { ASD FieldSpec } 3 \\
\text { spectrometer }\end{array}$ & $\begin{array}{l}\text { Loam, sand, and sandy } \\
\text { Loam, sand, and loam }\end{array}$ & - & $\begin{array}{l}\text { Reflectance decreased with increasing } \\
\text { soil moisture, except for oversaturated } \\
\text { soil moisture content } \\
\text { levels (N64\%) in the VNIR region of the } \\
\text { spectrum }\end{array}$ & [32] \\
\hline $\begin{array}{c}\text { ASD Pro FR } \\
\text { Portable } \\
\text { Spectroradiometer }\end{array}$ & $\begin{array}{l}10 \text { samples from all over } \\
\text { France }\end{array}$ & - & $\begin{array}{l}\text { For low soil moisture, } \\
\text { reflectance decreases when soil moisture } \\
\text { increases. Conversely, for the higher soil } \\
\text { moisture, reflectance increases when soil } \\
\text { moisture increases }\end{array}$ & [33] \\
\hline $\begin{array}{c}\text { ASD } \\
\text { Fieldspec-Pro } \\
\text { spectroradiometer }\end{array}$ & $\begin{array}{l}\text { Sandstone, sandy soil, and } \\
\text { loamy/clay soils }\end{array}$ & $0.05-0.25 \mathrm{~g}$ water $/ \mathrm{g}$ soil & $\begin{array}{c}\text { Spectral reflectance decreased } \\
\text { non-linearly with increasing moisture } \\
\text { content }\end{array}$ & [34] \\
\hline $\begin{array}{l}\text { ASD FieldSpec Pro } \\
\text { FRspectroradiometer and } \\
\text { FTIR Bruker Equinox } 55 \\
\text { spectrometer }\end{array}$ & $\begin{array}{l}\text { Natural soil samples from } \\
\text { France }\end{array}$ & $44-0 \%$ & $\begin{array}{l}\text { An increasing value of SMC leads to a } \\
\text { decrease in the reflectance level in the } \\
\text { entire optical domain }\end{array}$ & [35] \\
\hline ASD spectrometer & $\begin{array}{l}\text { Argicridisol, xeric andisol, } \\
\text { ustic mollisol, and aridic } \\
\text { entisol }\end{array}$ & $70-0 \%$ & $\begin{array}{l}\text { Reflectance decreased with increasing } \\
\text { moisture for all soils }\end{array}$ & [36] \\
\hline Exemplar LS Spectrometer & Dune sand & $5 \%$ & $\begin{array}{l}\text { Reflectance obtained as in the } \\
\text { infrared range and decreases with } \\
\text { increases in moisture }\end{array}$ & {$[26,28]$} \\
\hline
\end{tabular}

Table 4. Studies using IR cameras for water leak detection.

\begin{tabular}{|c|c|c|c|c|c|}
\hline Study Type & IR Camera & Soil Type & Pipe & Results & Reference \\
\hline Field & $\begin{array}{l}\text { ThermaCAM S } 60 \text { IR system } \\
\qquad(7.5-13 \mu \mathrm{m})\end{array}$ & - & Cast iron & $\begin{array}{l}\text { The IR camera successfully detected the } \\
\text { leaks as a thermal contrast at the pavement } \\
\text { surface that occurred in fall and spring } \\
\text { seasons, while it failed in detecting leaks } \\
\text { occurring in the summer and winter due to } \\
\text { high pavement temperature and the snow } \\
\text { coverage, respectively. }\end{array}$ & [37] \\
\hline Lab and field & $\begin{array}{l}\text { VarioCAM } 400 \mathrm{IR} \text { camera } \\
\quad(7.5-14 \mathrm{~mm})\end{array}$ & $\begin{array}{l}\text { Lab: clayey soil, Field: } \\
\text { crushed sand stone }\end{array}$ & PVC & $\begin{array}{l}\text { Multi-tier detection technology (GPR and } \\
\text { IR camera) was successful in detecting the } \\
\text { leaks in summer and winter seasons with a } \\
\text { small margin of error }(2.9-5.6 \%) \text { in } \\
\text { estimating leakage areas. }\end{array}$ & [38] \\
\hline $\mathrm{Lab}$ & $\begin{array}{l}\text { IRISYS Camera and Flir A310f } \\
\text { IR Camera }(7.5-13 \mu \mathrm{m})\end{array}$ & - & Plastic & $\begin{array}{l}\text { The cameras are able to visualize the leak } \\
\text { despite the leak itself being not being } \\
\text { evident on the surface by visual inspection. }\end{array}$ & {$[40]$} \\
\hline Field & Thermal Infrared Scanner & South Dakota area & - & $\begin{array}{l}\text { Leaks in buried rural water pipelines can } \\
\text { be detected using thermal infrared images } \\
\text { collected under proper conditions. }\end{array}$ & [41] \\
\hline Field & $\begin{array}{l}\text { Hydrogen leak detector, } \\
\text { Sensistor AB model } 8012\end{array}$ & Silty clay & PVC & $\begin{array}{l}\text { Thermography showed promise as a tool } \\
\text { for initial leak surveys. }\end{array}$ & [23] \\
\hline
\end{tabular}




\subsection{Objectives}

This research intends to:

1. Investigate the effectiveness of three NDTs (GPR, hand-held spectrometer, and an IR camera) in detecting leaks in WDI; and

2. Assess the factors that may affect the NDTs' response in detecting the water leaks.

The three main factors considered in the study are: soil moisture content $(2 \%, 5 \%$, and $10 \%$ ), pipe material (PVC, PE, and PPR), and types of leaks (vertical crack, hole, and faulty joint). These technologies are dynamic in nature [42]. The spectrometer has never been attempted for leak detection. Evaluation of factors affecting the performance of the NDTs to the authors knowledge was not previously investigated. As evidenced from literature, there has been limited research activities conducted using these technologies. The experimental setup developed in this study is novel in that it represents a simulation of the water distribution system in a much bigger scale than those observed in the literature. Novelty remains in that these experiments were conducted in open atmosphere, not in a controlled weather setting in the laboratory. Additionally, this research is novel in that the focus is on the evaluation of the factors affecting the performance of these leak detection technologies. It is especially crucial since versatility is essential in evaluating the efficiency of these technologies.

\section{Research Methodology}

An experimental setup carefully designed and built to simulate pipe leaks in underground conditions was used in the investigation. The following subsections describes the experimental setup and procedure used for this study.

\subsection{Experimental Setup}

The experimental setup, as shown in Figure 1, simulates a section of water distribution infrastructure. A dune sand filled box with four pipes was designed and built to investigate the potential of using NDTs for leak detection. The box was made of a non-conductive material (wood) to avoid reflection while using the GPR [43].

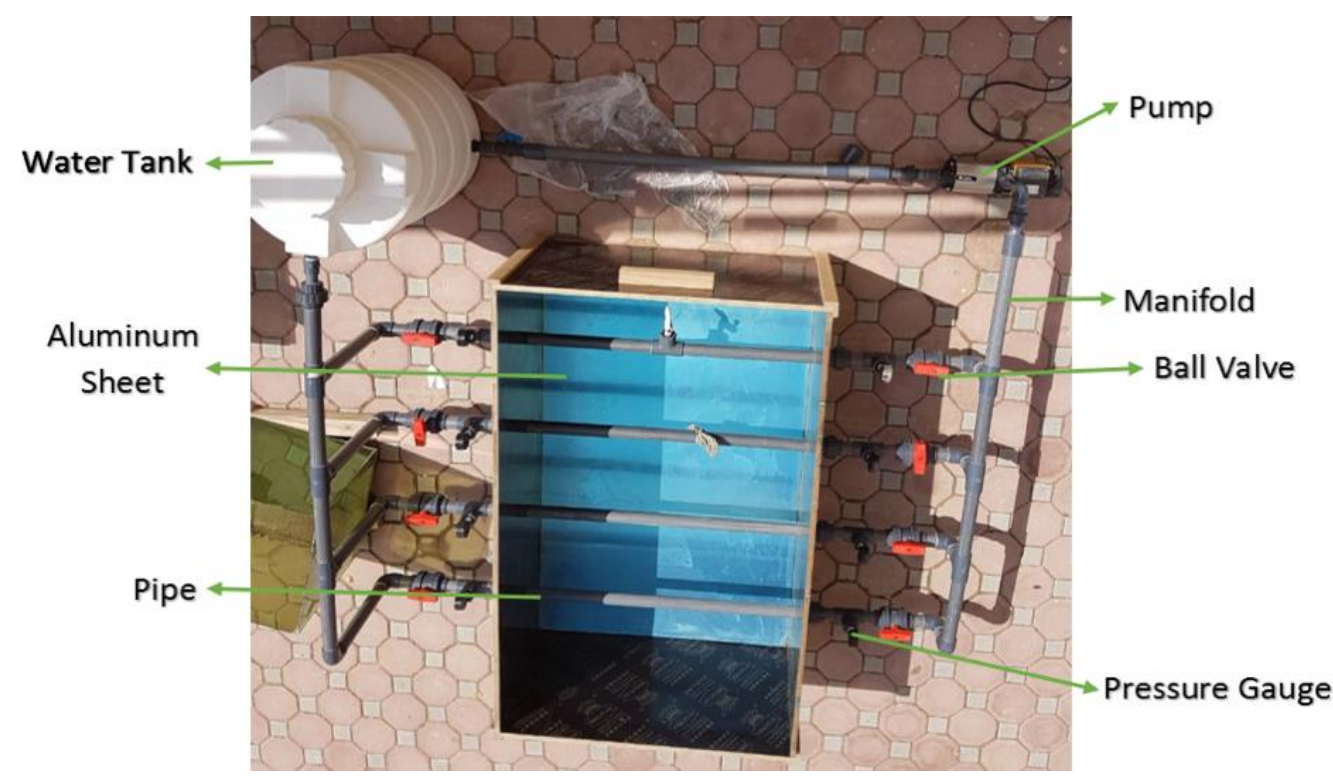

Figure 1. Experimental setup (top view).

Furthermore, a centrifugal pump of $0.75 \mathrm{hp}$ was connected to the four pipes by using a manifold to distribute water throughout the setup. Ball valves were fitted at the downstream and upstream of the pipes to control the flow of water through the pipes. In addition, pressure gauges of the range $0-250 \mathrm{kPa}$ were used to monitor the pressure in the 
pipes and maintain the same pressure in all the pipes throughout the experimental study. Finally, a water tank was connected to the pump and upstream of the four pipes to store and provide water in this water distribution infrastructure. The critical components of the experimental setup are further discussed in the following subsections.

\subsection{Dimensions of the Wooden Box}

The dimensions of the box illustrated in Figure 2 were chosen to be economical as well as optimum to enable testing using NDTs. The designed dimensions of the boxes in inches were $1676 \mathrm{mmL} \times 1016 \mathrm{mmW} \times 610 \mathrm{mmH}$. The pipes were fitted at a depth of $400 \mathrm{~mm}$ from the top surface of the wooden box, i.e., two-thirds of the total height of the box. The distance between the pipes was chosen based on the following two conditions. First, according to the handbook published by GSSI (GPR manufacturer), for a $1600 \mathrm{MHz}$ GPR, the minimum distance between two targets in concrete should be $76 \mathrm{~mm}$ to avoid any interferences in the images generated by the GPR [44]. Similar box dimensions and a test setup were used by $[13,23]$. Although the minimum distance between two targets in dune sand is unknown, the minimum distance condition as stated in the handbook should be satisfied. Second, the pipes should be placed at a considerable distance ( $305 \mathrm{~mm})$ apart because the water leaking from one pipe may quickly seep to the adjacent pipes, thereby affecting the data for the adjacent pipes. Plywood sheets were also placed vertically between the pipes to further prevent the seepage of water to the adjacent pipes.

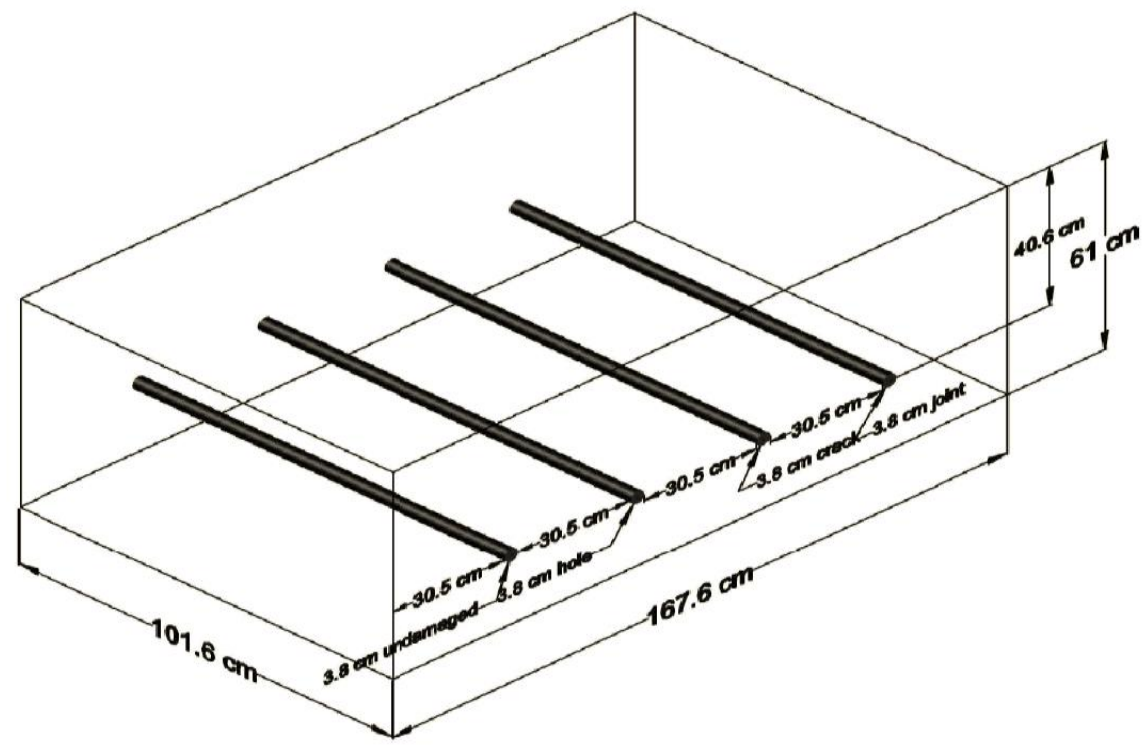

Figure 2. Detailed drawing of experimental setup.

\subsection{Pipes Used}

One of the objectives of this study was to assess the factors that may affect the ability of the NDTs for leak detection. Therefore, the pipe material and types of leaks were two of the three factors that were varied during experimentation. The diameter of all the pipes was $3.8 \mathrm{~cm}$. First, the three pipe materials used were: Polyvinyl chloride (PVC), polyethylene (PE), and polypropylene (PPR). Polymeric pipes are increasingly being employed in WDS [45]. Hence, polymeric pipes were employed in the present research study. Three wooden boxes were constructed, with each box containing four pipes of the same material as shown in Figure 3. 


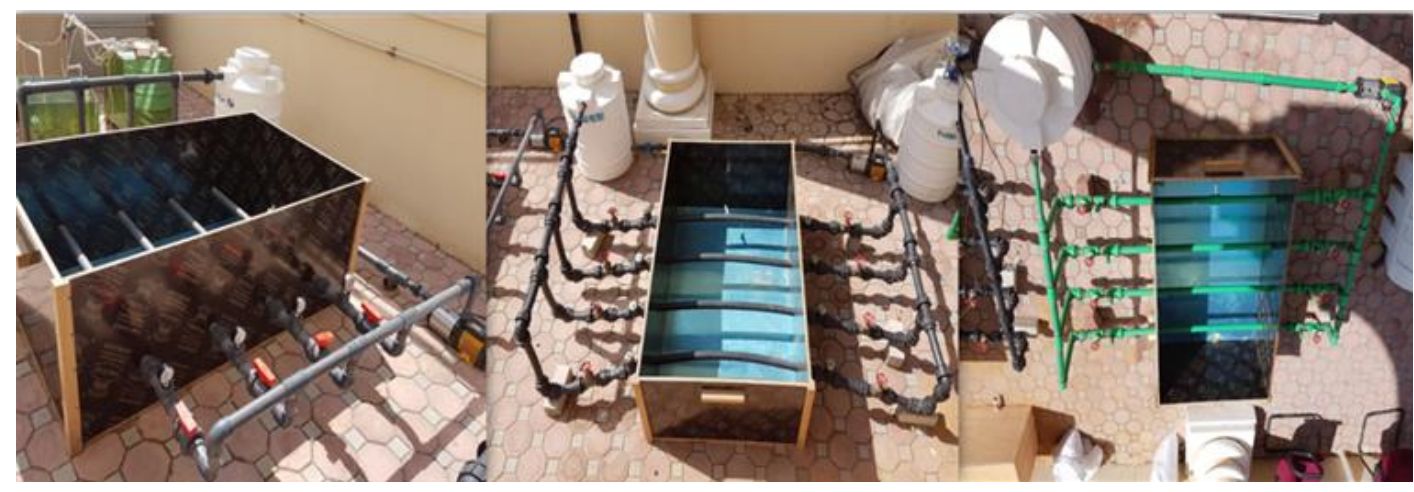

(a)

(b)

(c)

Figure 3. Setups with different types of pipe material: (a) PVC; (b) PE; and (c) PPR.

Second, different types of leaks were induced to evaluate the ability of the NDTs on wide-ranging pipe conditions. The first pipe was undamaged, the second contained a vertical crack, the third had a hole, and last pipe consisted of a faulty joint as illustrated in Figure 4 . To prevent water leaking from one pipe to seep to the adjacent pipes, the three simulated leaks were induced in different ends of the pipes. Thus, the vertical crack was induced on the left end of the second pipe (Figure 4a), the hole was drilled at the right end of the third pipe (Figure $4 \mathrm{~b}$ ), and the joint was installed at the center of the last pipe (Figure 4c).

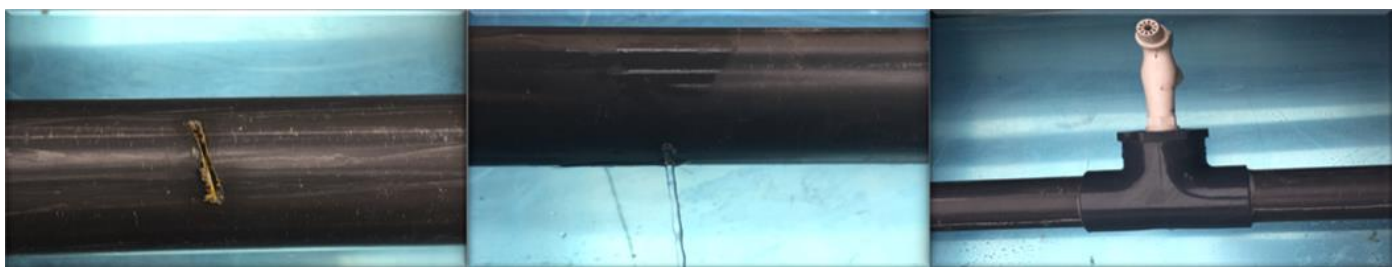

(a)

(b)

(c)

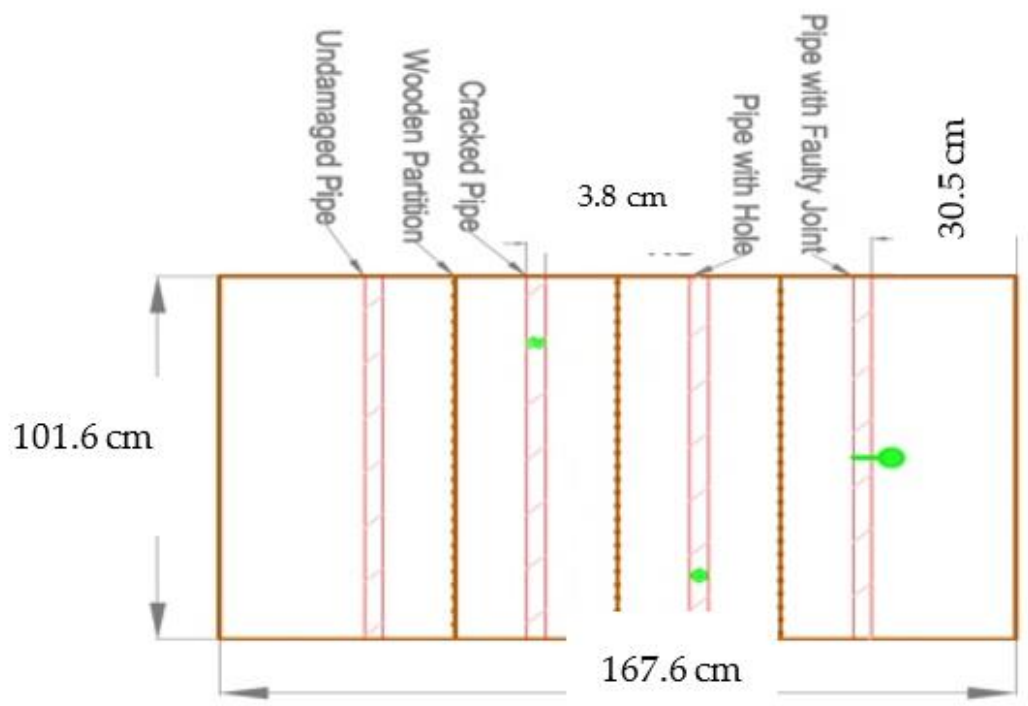

(d)

Figure 4. Leaks and their locations: (a) crack; (b) hole; (c) faulty joint; and (d) top view with leak position marked green. 
The pipes in the three boxes were buried in dune sand to replicate the common conditions of underground pipes in the water distribution infrastructure in the UAE. The two soil properties of interest are soil particle size distribution, which was obtained by performing sieve analysis on the dune sand, and the maximum dry density of the sand $\left(1689.41 \mathrm{~kg} / \mathrm{m}^{3}\right)$, which was obtained by performing the standard proctor test. All the soil procedures and tests were performed by following the ASTM standard. After determining the maximum dry density of the dune sand, it was compacted by using a custom-made vibrating plate compactor. Figure 5 shows the compaction of three layers to replicate the standard procedure of the proctor test. The total weight of dune sand could not be divided into three equal layers because the thickness of the first 1/3rd layer was less than the level of the pipe and the installation of the wooden partitions along with the large size of the compactor restricted the use of the compactor below the pipe level. The compactor was used along the width of the box. Figure 5 also presents the number of times (cycles) the compactor was passed over the sand to reach the desired compaction level. The degree of compaction of the dune sand for each box was calculated to be $90 \%$. Figure 6 illustrates the final view of the experimental setup after compaction. Even though the standard procedure should represent the actual soil conditions, a certain variability would exist in the field applications with actual site conditions.

\section{Layer 3}

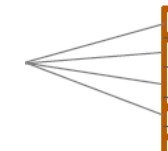

$35 \%$ of Layer 2

Layer $1+65 \%$ of Layer 2

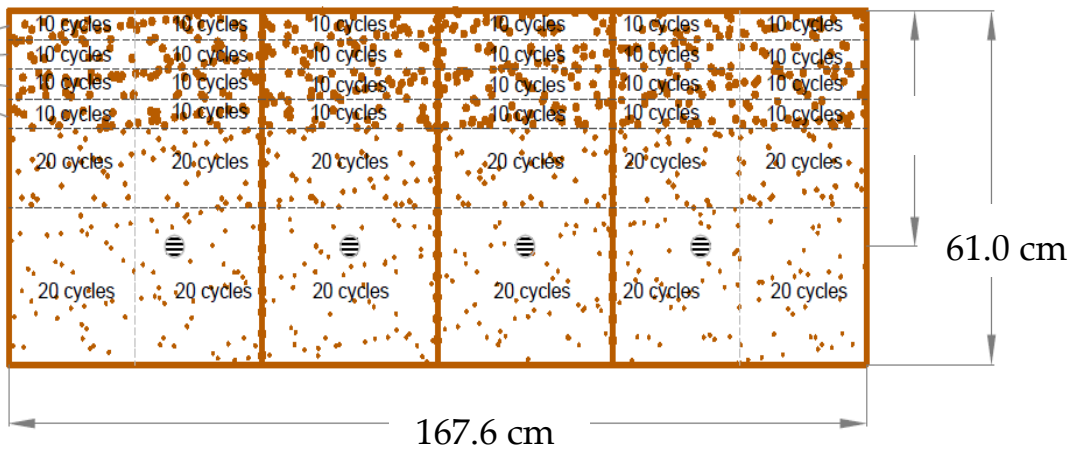

Figure 5. Compaction pattern.

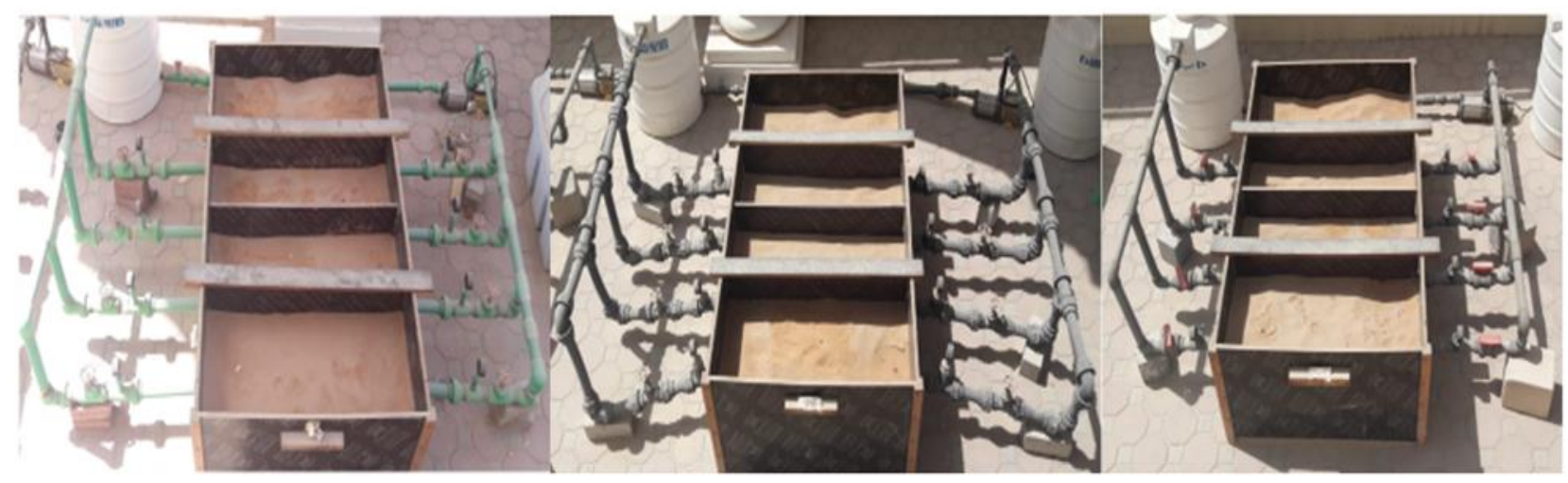

(a)

(b)

(c)

Figure 6. Setups compacted with dune sand: (a) PPR, (b) PE, and (c) PVC.

The levels of $\mathrm{MC}$ of the dune sand were the last factor that was varied to determine its effect on the ability of the NDTs to detect leakage. The experimental study was conducted at the following three approximate moisture content levels of dune sand: $2 \%, 5 \%$, and $10 \%$. The first round of experiments was performed on air-dried dune sand (tested at $2 \%$ moisture content). Next, a calculated amount of water was sprinkled on the top surface of the boxes to achieve a 5\% moisture content in dune sand. Similarly, additional water was added to achieve the final $10 \%$ moisture content in dune sand. However, small variations 
in the soil moisture content were expected as some water may be lost via evaporation, the sand may absorb water from the air on humid days, etc. The moisture content of the dune sand was tested using the standard approach of the oven-dry test by taking two samples from the mid-height of the sand layer near the shorter edges of the box before starting the first, second, and third round of the experiment. Several trials were made to achieve an accurate moisture content level in the experimental setup.

\subsection{Description of Equipment}

Three different types of NDTs were used to accomplish the objective of this study. These were:

1. GPR: Geophysical Survey Systems, Inc. (GSSI), Nashua, NH, USA, Structure Scan Mini GPR, as shown in Figure 7a, with an antenna frequency of $1.6 \mathrm{GHz}$ and penetration depth of about $50 \mathrm{~cm}$. RADAN software was used to process and analyze the scans obtained from the GPR;

2. Spectrometer: in this study, the Exemplar LS Spectrometer, as illustrated in Figure $7 \mathrm{~b}$, which has a wavelength range of $0.2-0.85 \mu \mathrm{m}$, was used. The Exemplar LS Spectrometer displays real-time data and requires the use of specific software for data analysis (BWSpec software); and

3. IR Camera: the camera used in this study was the FLIR T420 depicted in Figure 7c, which has a wavelength range of $7.5-14.0 \mu \mathrm{m}$. The device has a native resolution of $464 \times 348$. The minimum focus distance is $24^{\circ}$ lens: $0.5 \mathrm{~m}$. IFOV in the manufacturing facility is $42^{\circ}$ lens. However, the focal length is not provided in these cameras because of the relationship between the horizontal FOV and focal length.

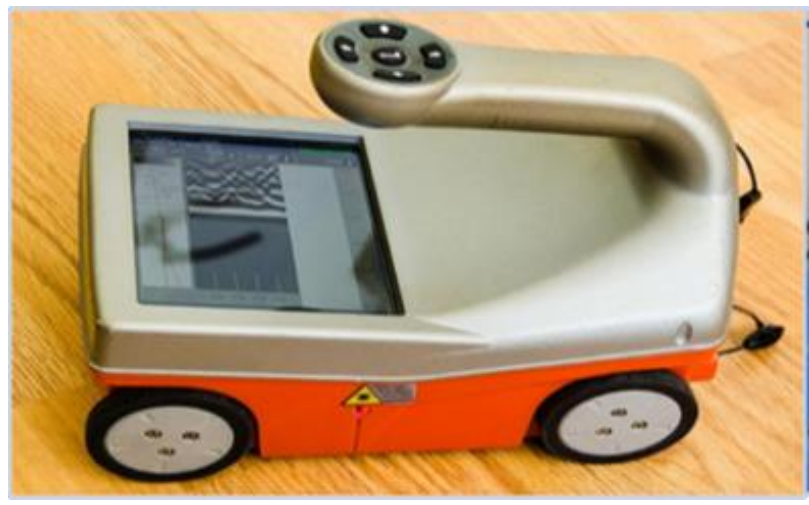

(a)

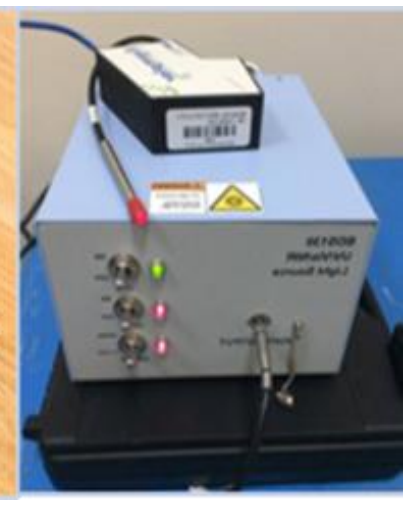

(b)

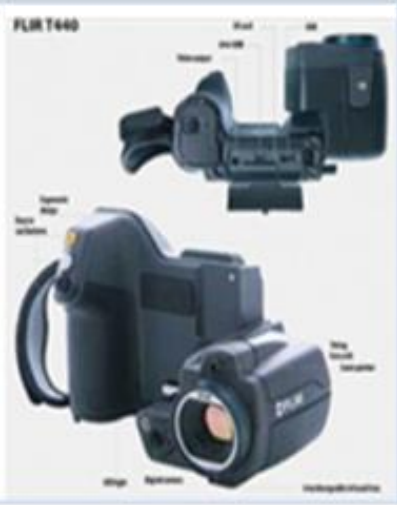

(c)

Figure 7. (a) GPR; (b) Exemplar LS Spectrometer; and (c) FLIR T420.

\subsection{Procedure}

An experimental plan was developed for this study (Table 5). First, all the three boxes were filled with air-dried dune sand (with $2 \%$ moisture content) and the first set of data was collected. Consequently, the following sets of data were collected by increasing the moisture content of the dune sand in all the three boxes. Experiments were conducted with a temperature ranging from $25^{\circ} \mathrm{C}$ to $40{ }^{\circ} \mathrm{C}$.

After the experimental setup was prepared, water was pumped through the setup. Then, the three equipment devices were tested on each pipe in the same sequence for all the tests (GPR was run first, then Exemplar LS Spectrometer, and finally FLIR T420 IR Camera). A reference reading was taken at the beginning of the experiment of the undamaged pipe to represent the condition of pipes without leaks. 
Table 5. Experimental plan.

\begin{tabular}{ccccc}
\hline \multirow{2}{*}{ Sequence of Tests } & Moisture Content & \multicolumn{3}{c}{ Pipe Material } \\
\cline { 3 - 5 } & & PVC & PE & PPR \\
\hline Round 1 & $5 \%$ & $\sqrt{ }$ & $\sqrt{ }$ & $\sqrt{ }$ \\
\hline Round 2 & $10 \%$ & $\sqrt{ }$ & $\sqrt{ }$ & $\sqrt{ }$ \\
\hline Round 3 & & $\sqrt{ }$ &
\end{tabular}

Each of the three NDTs mentioned above had a different survey plan. GPR was a line form of testing where the GPR was run along the length of the pipe, spectrometers employed a point-form of testing where data was collected from the established test points, and the IR camera covered large areas. Figure 8 illustrates the survey plan for each equipment device. A $3 \mathrm{~mm}$ wooden sheet was placed on the compacted soil to run the GPR along the four pipes. Three GPR scans were conducted for each pipe (along the pipe length, to the left, and to right of the pipe), as shown in Figure 8a. The data was collected every hour and the total duration of the experimentation was three hours. Hence, a total of three readings per pipe were taken. The direction in which the GPR was utilized on the pipes has been depicted using a blue arrow in Figure 8a. The following procedure was followed to process the GPR images.

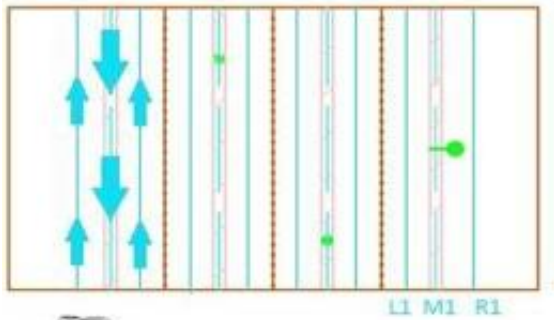

a)

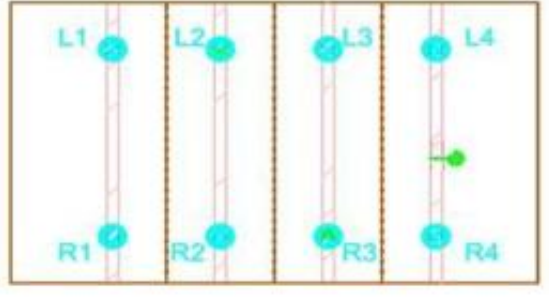

b)

c)

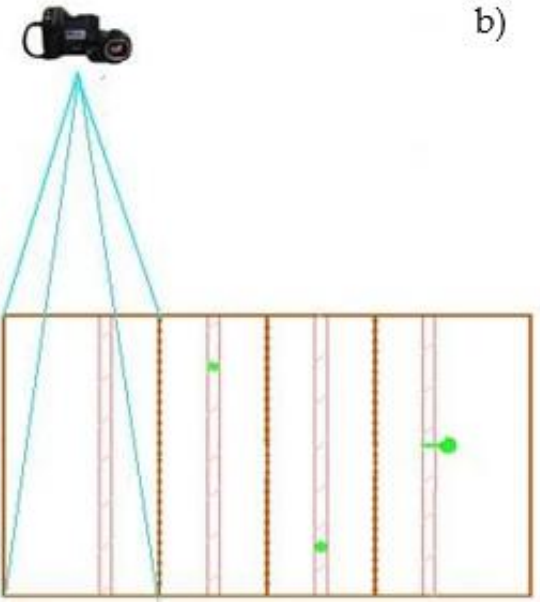

Figure 8. Survey plan for the experiments: (a) GPR; (b) spectrometer; and (c) IR camera.

The dielectric constant of the dry sand was determined utilizing a metal plate which was placed at a known depth (bottom of the test box).

In addition to the visual inspection of the images, Equations (2) and (3) were used to calculate the travel time of the pulse and confirm the existence of potential leakage.

$$
\mathrm{V}=\mathrm{C} / \operatorname{Er}^{1} \frac{1}{2}
$$


where $\mathrm{V}=$ velocity in the medium $(\mathrm{m} / \mathrm{s}), \mathrm{C}=$ velocity in free space $\left(3 \times 10^{8} \mathrm{~m} / \mathrm{s}\right)$, and $\mathrm{Er}=$ the relative dielectric constant. Addditionally,

$$
\mathrm{Er}=\mathrm{\epsilon} / \mathrm{\epsilon} 0
$$

where $\mathrm{E}=$ the dielectric constant of the material $(\mathrm{F} / \mathrm{m})$ and $\mathrm{E} 0=$ the dielectric constant of air, which is $8.85 \times 10^{-12}(\mathrm{~F} / \mathrm{m})$.

A similar procedure was followed by the authors and others $[15,46-50]$.

Furthermore, for each spectrometer, it was tested at two locations $(\mathrm{L}=$ left and $\mathrm{R}=$ right) for each pipe, as shown in Figure 8b. Finally, IR images were taken for each pipe, as illustrated in Figure 8c.

For processing of the IR images for leak detection, the region-growing algorithm (RGA) was used. RGA is a simple image segmentation method initiated from a seed pixel.

\section{Results and Discussion}

\subsection{GPR}

Equations (2) and (3) were used during the calibration and post-processing to identify locations with potential leakages. Table 6 summarizes the dielectric constants for the soil used in the current study at different moisture contents. The dielectric constants were determined using the known distance of the steel plate used during calibration and the propagation velocity $(\mathrm{V})$ of the electromagnetic waves for each case. The dielectric values were used during the post-processing to interpret the data/images. However, due to the space limitations and objectives of the investigation, detailed discussion of the processing of the GPR images was not possible.

Table 6. Dielectric constants at different moister contents.

\begin{tabular}{cc}
\hline Water Content (\%) & Dielectric Constant \\
\hline 0.00 & 4.0 \\
\hline 2 & 4.8 \\
\hline 5.00 & 8.5 \\
\hline
\end{tabular}

The GPR was used on pipe 1 and pipe 2 to detect leaks in the pipes. However, the GPR could not be used on pipe 4 (faulty joint). This is due to the rate of water leakage from the joint that was higher in comparison to pipe 2 (crack) and pipe 3 (hole). Consequently, the water quickly reached the surface of the sand, forming surface ponding. This scenario represents one of the conditions (limitations) that the GPR cannot be used in because of the conductivity and increasing signal attenuation, therefore no images will be produced. Hence, experimental data presented will not include data for pipe 4.

The data was collected every hour and the total duration of the experimentation was three hours. A total of three scans per pipe were taken. In addition to this, the readings were taken to the left, center, and right of the pipe to ensure a complete coverage of the area surrounding the pipe. Thus, in Figure 9, it was observed that each time interval has three GPR images: left, center, and right. The leaks were detected in the images obtained from the GPR. In addition, Equations (2) and (3) were used to calculate the travel time of the pulse and confirm the existence of potential leakage. With an increase in the duration of leak, the development of haze in the GPR images indicates the presence of leaks, which have been circled in red. It was observed that the GPR was able to detect leaks in the following cases: all three pipe materials and the pipes with the hole and crack. As mentioned before, the GPR was not used for pipe 4 (faulty joint). However, the development of surface ponding itself was an indication of leakage.

Figure 10 presents the data obtained from the GPR scans on the setups when the moisture content of the dune sand was approximately $5 \%$. Like the previous case (moisture content $=2 \%$ ), from Figure 10, it was observed that the GPR was able detect leaks in all 
three pipe materials and the two types of pipe damages (crack and hole). However, it was observed that the visual inspection of images to find the leaks was more strenuous when the moisture content was $5 \%$ in comparison to the case in which the moisture content of the dune sand was $2 \%$. Figure 11 presents the data obtained for the GPR when the moisture content of the dune sand was $10 \%$. Contrary to the previous cases, the GPR was only able to detect the leak in pipe 2 (crack) in the PPR setup and in pipe 3 (hole) in the PE setup. It may be this way because a high saturation of soil reduces the ability of GPR to identify the contrast between the water coming out of the leak and the soil moisture.

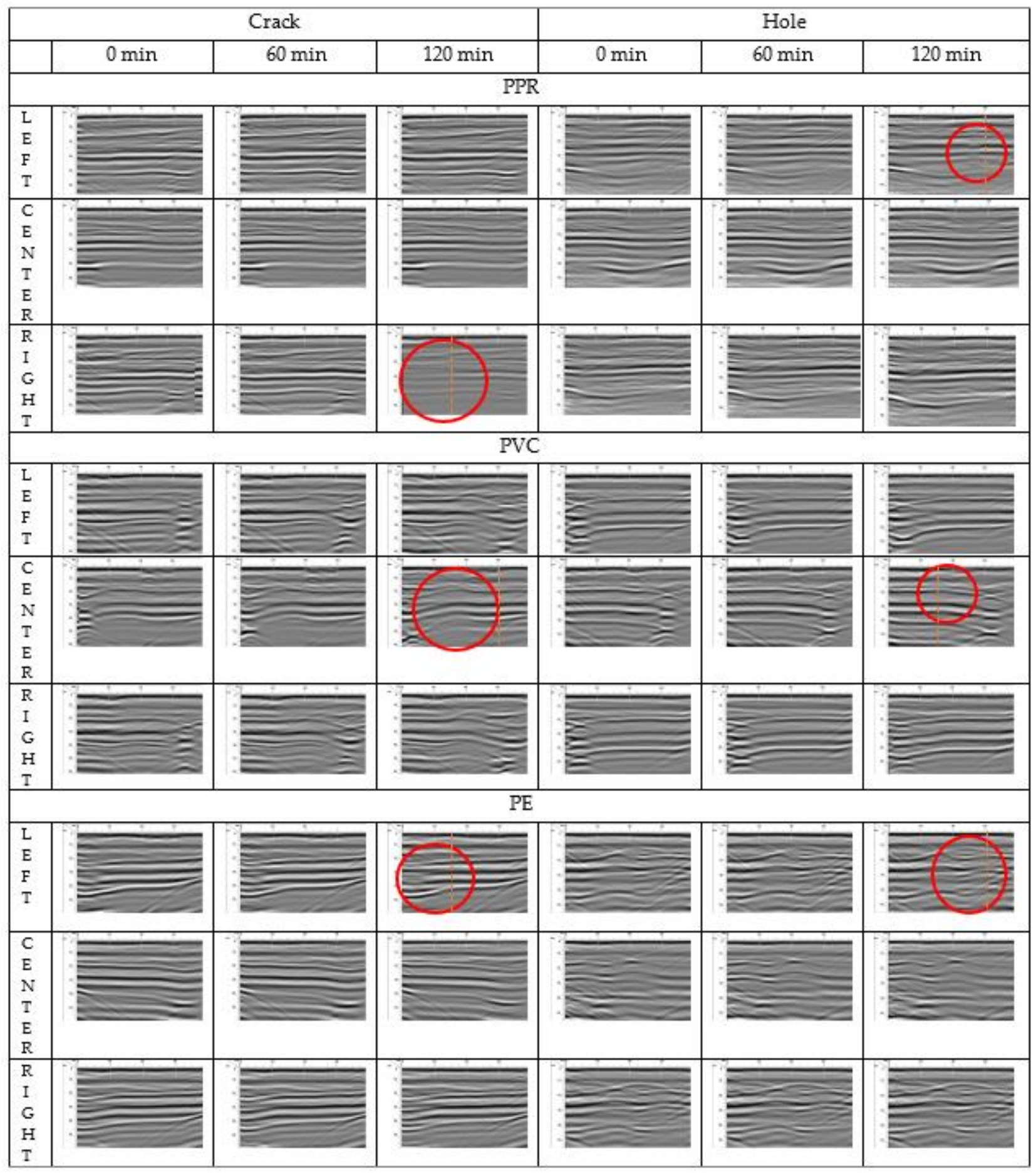

Figure 9. GPR images obtained on PPR, PVC and PE setup with $2 \%$ soil moisture content. 


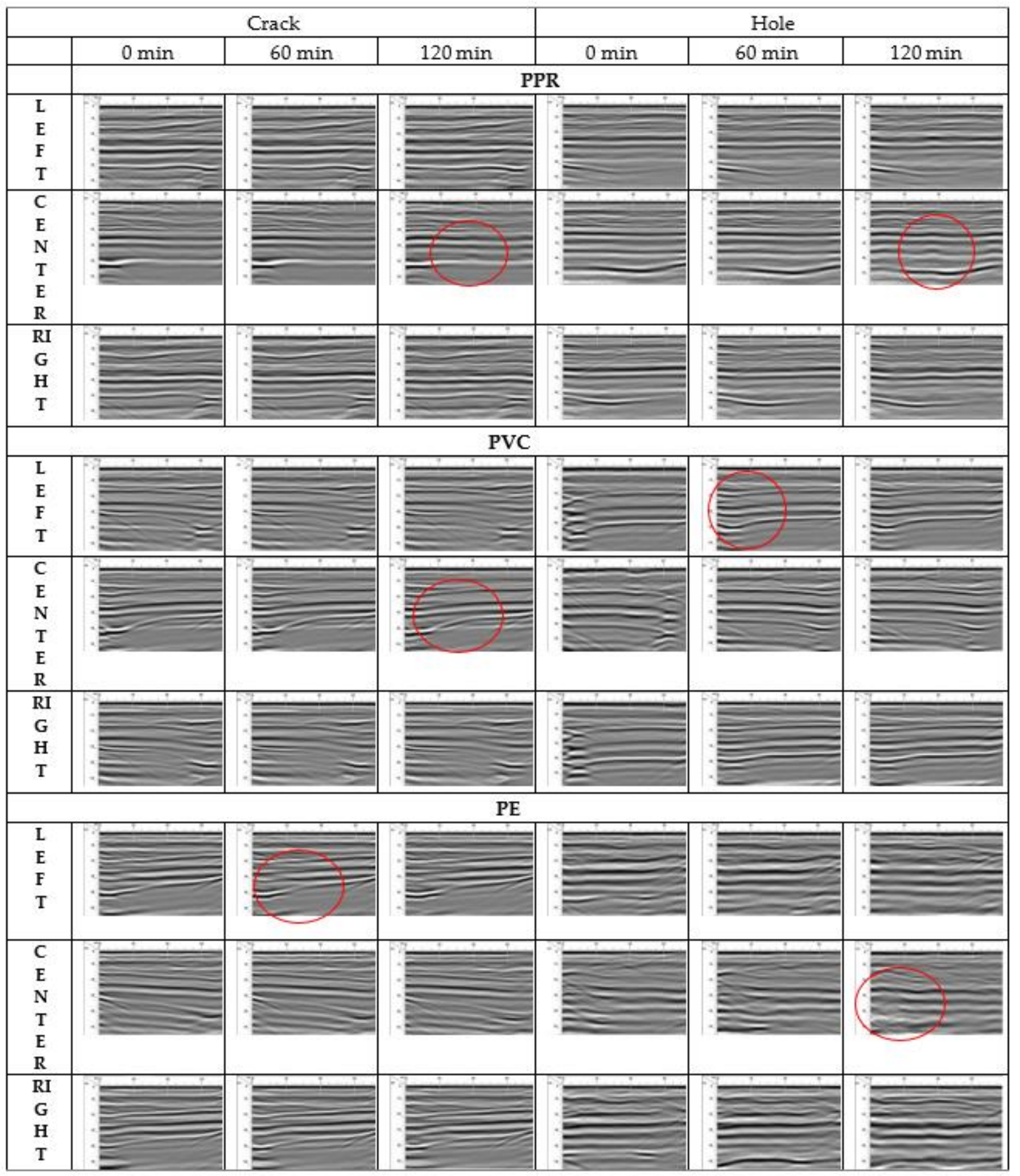

Figure 10. GPR images obtained on PPR, PVC and PE setup with 5\% soil moisture content. 


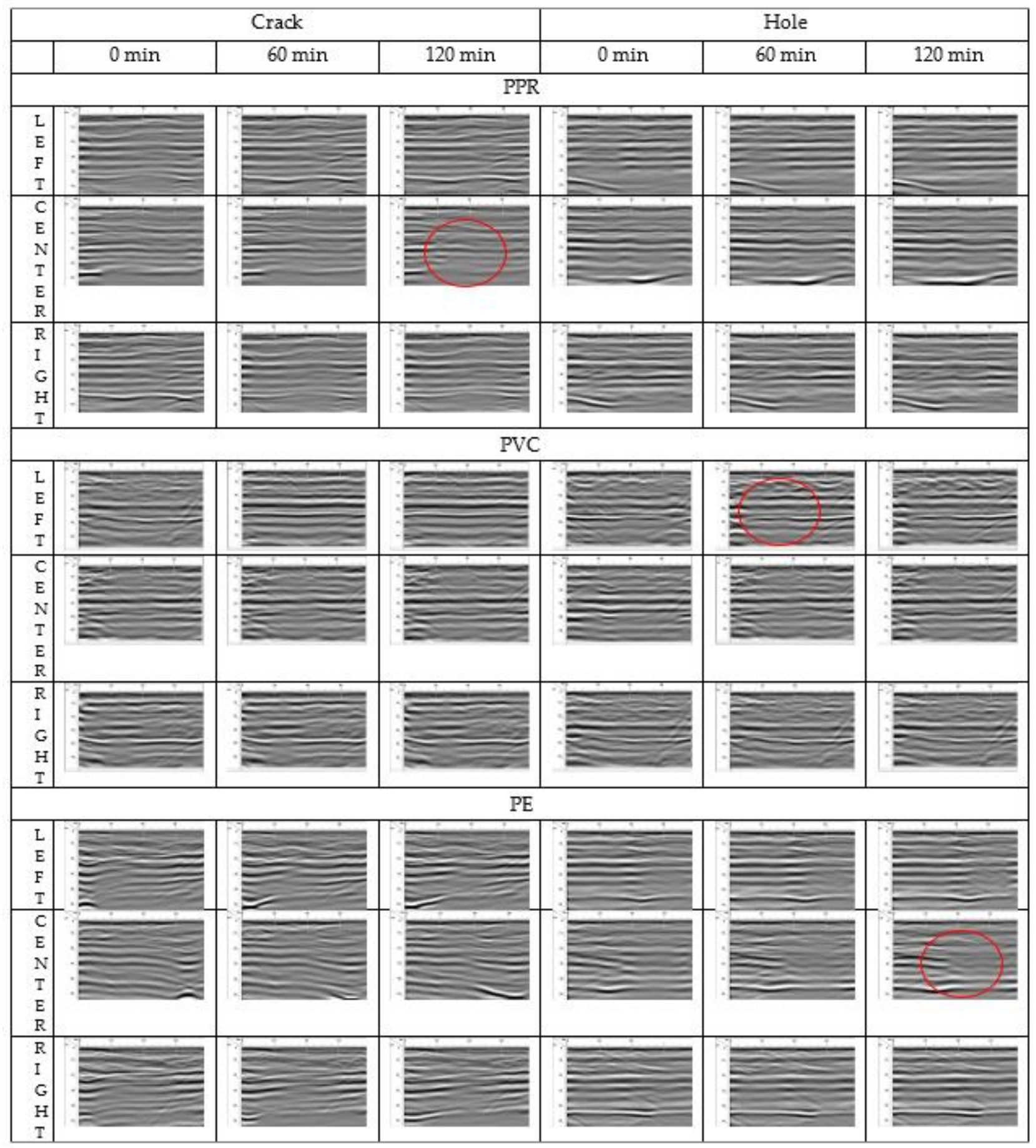

Figure 11. GPR images obtained on PPR, PVC and PE setup with 10\% soil moisture content.

\subsection{IR Camera}

The experiment was designed such that one IR video could be captured hourly for each pipe. The total experimentation time was $3 \mathrm{~h}$, hence three IR images were produced for a given pipe. Figure 12 presents the IR images collected for the pipes when the moisture content of the sand was approximately $2 \%$. The RGA was used to process the IR images by utilizing the image histogram to identify the coolest pixel in the image and use it as the seed pixel. Then, the neighboring pixels of the initial seed pixel were examined to determine if they can be added to the region. In this study, the three images taken for every pipe type over a three-hour period were processed using the coolest pixel in each image (i.e., the pixel with the lowest temperature). Then, the region-growing algorithm was implemented on 
each image using image variance as the threshold criteria for accepting or rejecting pixels. Then, the resulting regions in the three images were compared. Leak are identified only for the resulting regions that were increasing with time. If the three seed pixels are at the same location, a unique leak location is identified. Otherwise, the locations of the three seed pixels are potential locations of the leakage. The RGA was implemented in ArcGIS 6.5 using the Reclassifier tool in the Classification Wizard. The essence of using the spectrometer was to identify the wavelength(s) that are sensitive to the identification of the leaks through moisture so that an appropriate imaging device with these identified wavelength(s) can be used in the future. The criteria used for the detection of leaks in the spectrometer considers any reflectance/transmittance of less than $50 \%$ in wavelengths larger than $0.70 \mu \mathrm{m}$ as an indication. Figure 13 below demonstrates the RGA method by showing the location of the seed pixel in a sample image and the region created using the RGA criteria mentioned above. Note that in Figure 13c, the number of pixels that compose the region created the surroundings of the seed pixel. It is evident that the IR camera was able to robustly detect leaks in all pipe materials (PE, PPR and PVC) for all of the tested leak types (crack, hole and faulty joint) when the soil moisture content was $2 \%$. Hot spot analysis of the IR images has been employed to detect the leaks. As observed from the IR images in Figure 12, there was a formation of blue spots in the IR image with time. These blue spots are locations where the temperature was reduced. This temperature reduction can be explained because of the increase in the moisture content of the sand surrounding the leak. Hence, as the time of the leak increases, the amount of water leaking to the surrounding sand increases, thereby, increasing the blue spots in the IR image. Similarly, Figure 14 shows the IR images obtained when the moisture content of the soil was approximately $5 \%$. The IR camera was successful in detecting leaks in the pipes when the moisture content was $5 \%$. Contrary to this, the IR camera was unable to detect the leaks when the moisture content of the soil was approximately $10 \%$, as shown in Figure 15. Additionally, unlike the GPR, the IR camera could be utilized on pipe 4 (faulty joint) as the images are captured from a distance, safeguarding the camera from the water stagnated on the surface of pipe 4 . The increase in the percentage of soil moisture reduces the ability of the IR camera to distinguish between the temperature contrasts between the soil and leaking water. However, IR images with high resolution may be able to capture this.

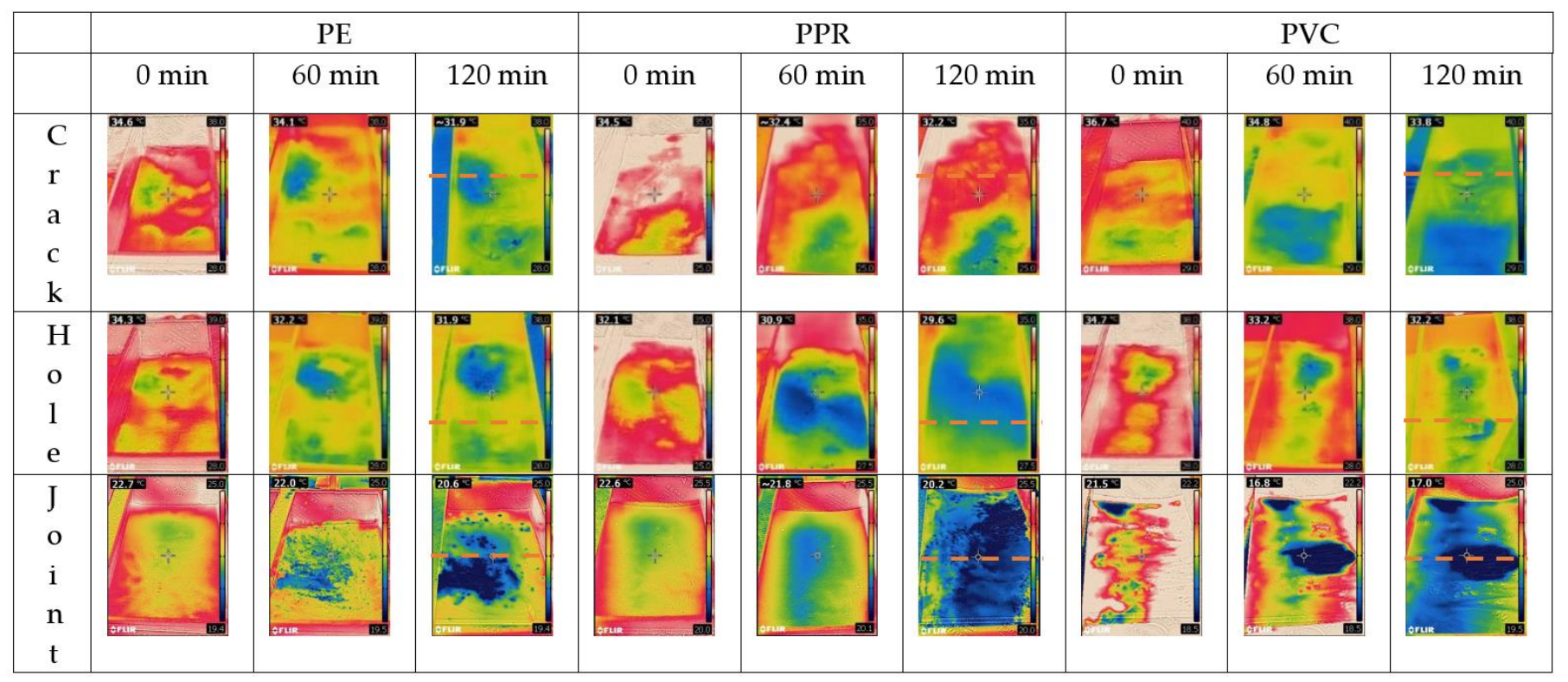

Figure 12. IR images obtained on PPR, PVC and PE setup with $2 \%$ soil moisture content. 


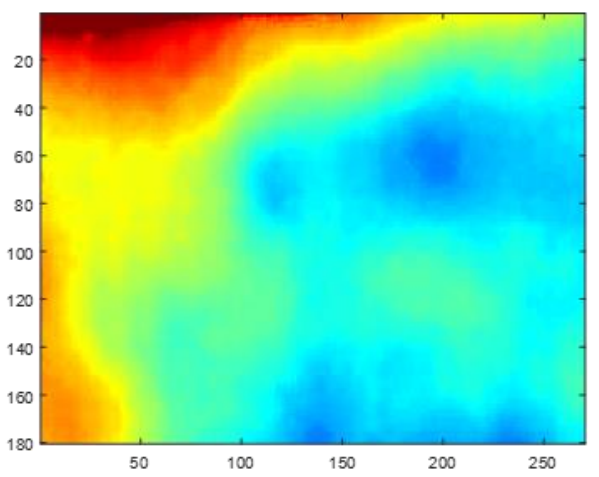

(a)

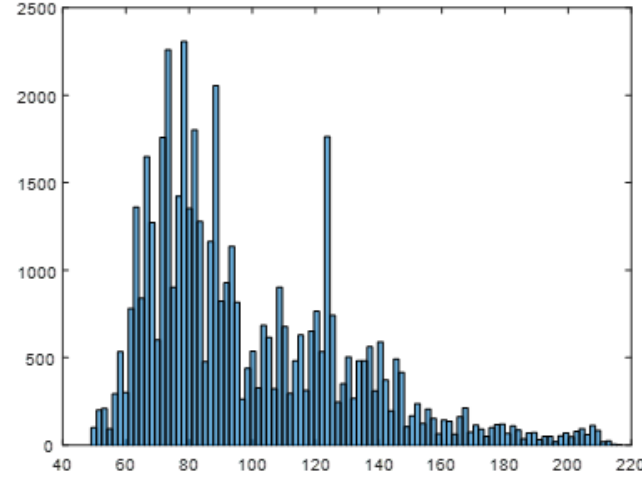

(b)

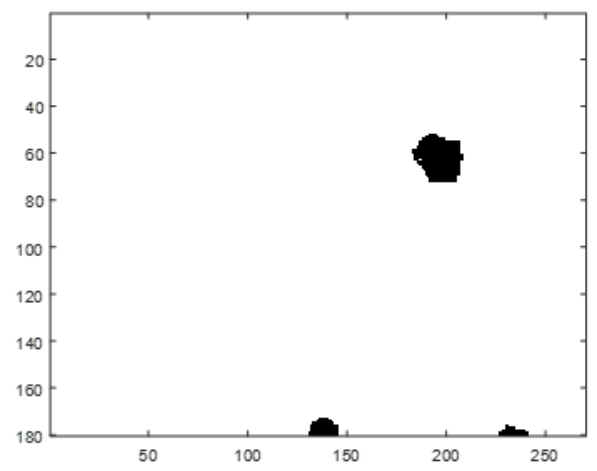

(c)

Figure 13. (a) Sample IR image; (b) image histogram; and (c) identified leakage locations.

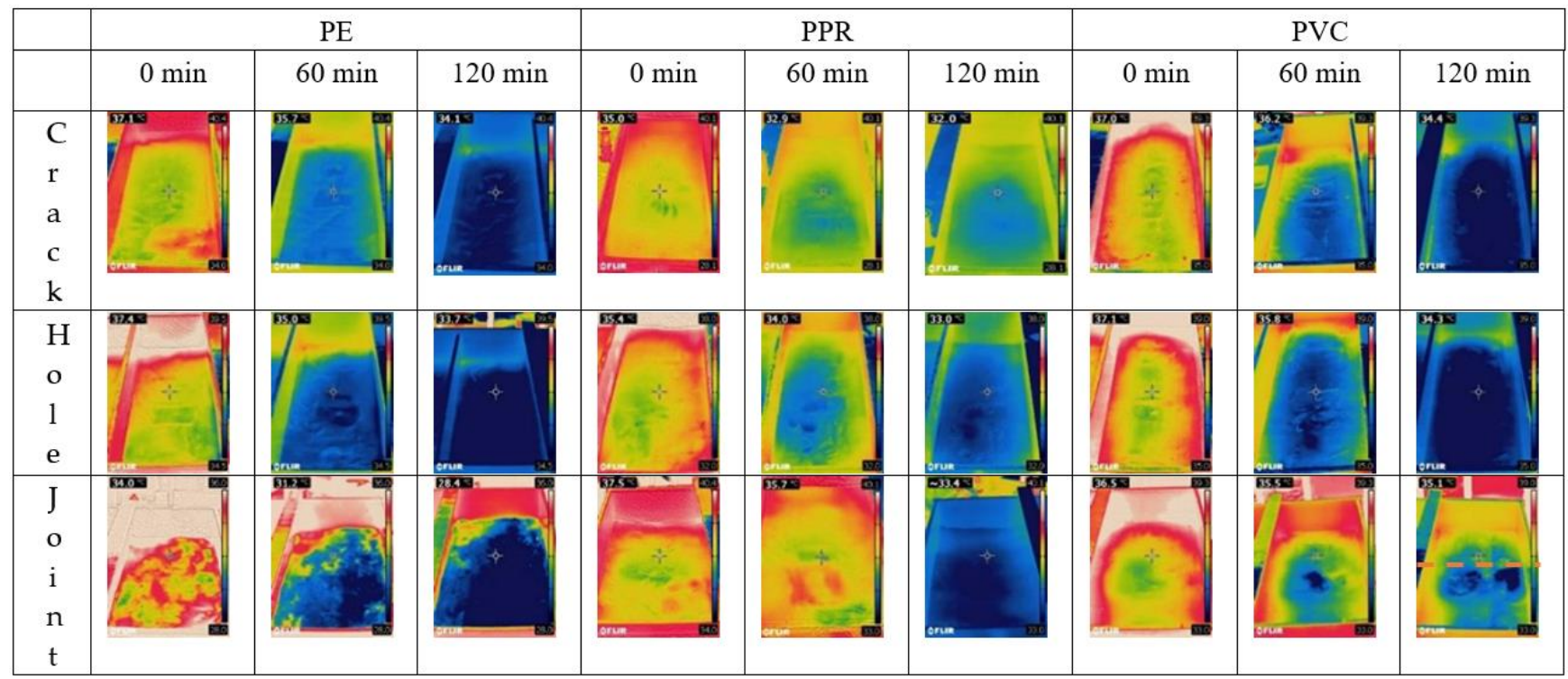

Figure 14. IR images obtained on PPR, PVC and PE setup with 5\% soil moisture content. 


\begin{tabular}{|c|c|c|c|c|c|c|c|c|c|}
\hline & \multicolumn{3}{|c|}{ PE } & \multicolumn{3}{|c|}{ PPR } & \multicolumn{3}{|c|}{ PVC } \\
\hline & $0 \mathrm{~min}$ & $60 \mathrm{~min}$ & $120 \mathrm{~min}$ & $0 \min$ & $60 \mathrm{~min}$ & $120 \mathrm{~min}$ & $0 \mathrm{~min}$ & $60 \mathrm{~min}$ & $120 \mathrm{~min}$ \\
\hline C & & & & 20302 & 5840 & 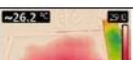 & $\frac{52325}{65}$ & & \\
\hline $\begin{array}{l}\mathrm{r} \\
\mathrm{a}\end{array}$ & & & & & & & & & \\
\hline $\mathrm{k}$ & & & & & & & & & \\
\hline $\mathrm{H}$ & & & & & & & & & 20,98 \\
\hline o & & & & & & & & & \\
\hline 1 & & & & & & & & & \\
\hline & & & & & $\frac{10098}{2028}$ & 221.02 & $\frac{106}{1268}$ & 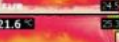 & \\
\hline $\mathrm{O}$ & & & & & & & & & \\
\hline $\begin{array}{l}1 \\
n\end{array}$ & & & & & & & & & \\
\hline$t$ & & & & & & & & & \\
\hline
\end{tabular}

Figure 15. IR images obtained on PPR, PVC and PE setup with $10 \%$ soil moisture content.

\subsection{Spectrometer}

The amount of water leaking from the pipes gradually increased with the increasing amount of water passed through the pipe. This leaking water was absorbed by the soil surrounding the pipes in the experimental setup and, hence, increased the soil moisture content. As a result, the reflectance recorded by the spectrometer was expected to decrease with the increase in time. This expectation was met based on the results of the experiment. The reflectance obtained by the spectrometer at wavelengths higher than $0.70 \mu \mathrm{m}$ significantly decreased when compared to the reading taken at time zero and the reading taken after $60 \mathrm{~min}$.

A sample reflection/transmission plot like those shown in Figure 16 demonstrates the changes against different wavelengths. The results obtained for pipe 2 (pipe with a crack) and pipe 3 (pipe with a hole) for all three pipe materials (PPR, PVC and PE) at 2\% moisture content are shown in Figure 17. Based on the results, the spectral reflectance decreased at wavelengths greater than $0.70 \mu \mathrm{m}$ with the moisture content increased. These findings agree with findings in literature which suggests that the decrease in reflectance with the increase in moisture content is more noticeable in the infrared bands [23]. The reflectance obtained at wavelengths less than $0.70 \mu \mathrm{m}$ was observed to decrease; however, the decrease was inconsistent, making it difficult to draw any conclusion. Furthermore, the spectrometer was not able to consistently identify leaks in the pipes when the moisture content was $5 \%$ and $10 \%$.

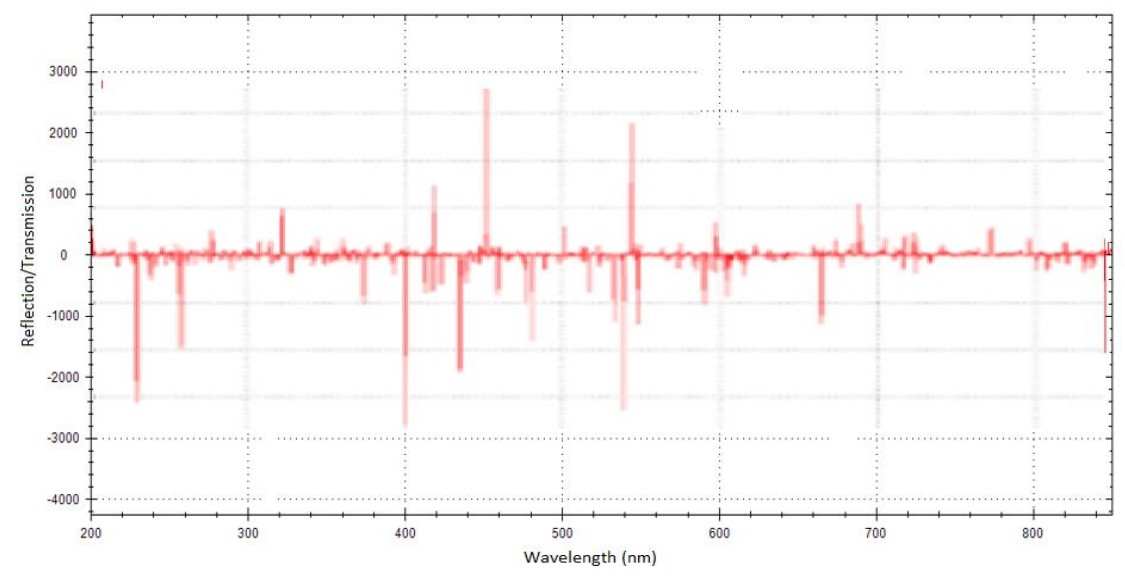

Figure 16. Spectrometer reflectance obtained from the PE pipe with a crack (right) at $2 \%$ moisture content. 


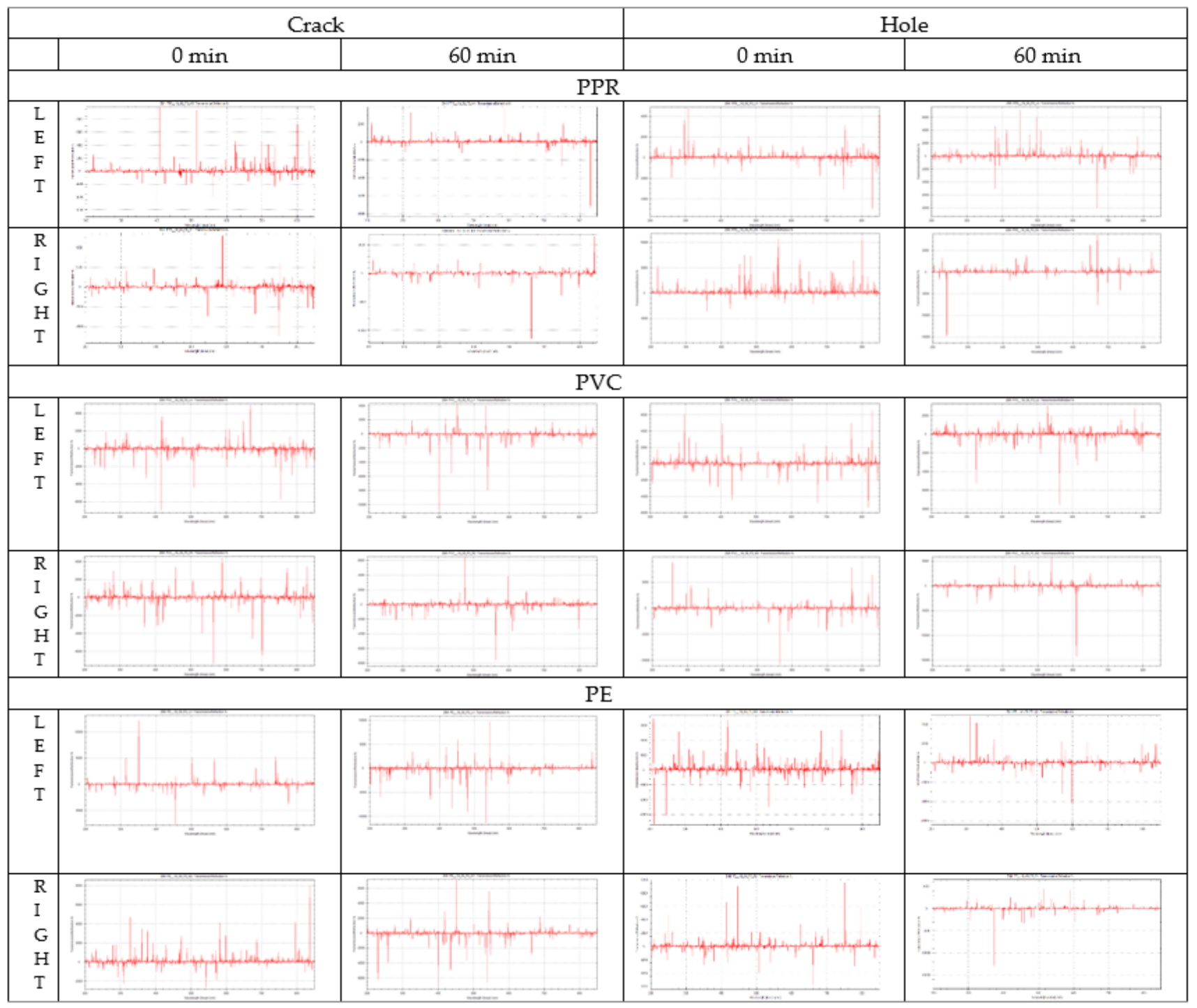

Figure 17. Spectrometer reflectance obtained against different wavelengths on PPR, PVC and PE setup with $2 \%$ soil moisture content.

The spectrometer could identify leaks from the crack and hole in all pipe material at $2 \%$ sand moisture content. However, the spectrometer was unable to detect the leak from the joint due to the accumulation of water on the surface of the soil that resulted in ponding. As a result, it was not possible to use the instrument. Nevertheless, the leak in the fourth pipe was detected by just visual inspection as the water from the faulty joint had reached the surface.

\subsection{Summary}

Table 7 presents a summary of the leak detection potential of the NDTs for all the types of pipes (PVC, PE, and PPR) at different soil moisture contents. It was found that all NDTs were able to detect leaks in pipes; however, the success rate of the NDTs differed for each NDT. 
Table 7. Summary of leak detection potential of NDTs.

\begin{tabular}{|c|c|c|c|c|c|c|c|c|c|}
\hline \multirow{2}{*}{$\begin{array}{l}\text { Type of } \\
\text { Leak }\end{array}$} & \multicolumn{3}{|c|}{ 2\% Moisture Content } & \multicolumn{3}{|c|}{ 5\% Moisture Content } & \multicolumn{3}{|c|}{$10 \%$ Moisture Content } \\
\hline & GPR & Spectrometer & IR Camera & GPR & Spectrometer & IR Camera & GPR & Spectrometer & IR Camera \\
\hline \multicolumn{10}{|c|}{ PVC } \\
\hline Crack & $\checkmark$ & $\checkmark$ & $\checkmark$ & $\checkmark$ & $\checkmark$ & $\checkmark$ & $x^{*}$ & $x *$ & $x$ \\
\hline Hole & $\checkmark$ & $\checkmark$ & $\checkmark$ & $\checkmark$ & $x^{*}$ & $\checkmark$ & $\checkmark$ & $x^{*}$ & $x$ \\
\hline Faulty joint & $x^{*}$ & $x^{*}$ & $\checkmark$ & $x^{*}$ & $x^{*}$ & $\sqrt{ }$ & $x^{*}$ & $x^{*}$ & $x^{*}$ \\
\hline \multicolumn{10}{|c|}{ PE } \\
\hline Crack & $\checkmark$ & $\checkmark$ & $\checkmark$ & $\checkmark$ & $x^{*}$ & $\checkmark$ & $x$ & $x^{*}$ & $x$ \\
\hline Hole & $\checkmark$ & $\checkmark$ & $\checkmark$ & $\checkmark$ & $x^{*}$ & $\checkmark$ & $\checkmark$ & $x^{*}$ & $x$ \\
\hline Faulty joint & $x^{*}$ & $x^{*}$ & $\checkmark$ & $x^{*}$ & $x^{*}$ & $\checkmark$ & $x^{*}$ & $x^{*}$ & $x^{*}$ \\
\hline \multicolumn{10}{|c|}{ PPR } \\
\hline Crack & $\checkmark$ & $\checkmark$ & $\checkmark$ & $\checkmark$ & $x^{*}$ & $\checkmark$ & $\checkmark$ & $x^{*}$ & $x$ \\
\hline Hole & $\checkmark$ & $\checkmark$ & $\checkmark$ & $\checkmark$ & $\checkmark$ & $\checkmark$ & $x$ & $x^{*}$ & $x$ \\
\hline Faulty joint & $x^{*}$ & $x^{*}$ & $\checkmark$ & $x^{*}$ & $x *$ & $\checkmark$ & $x^{*}$ & $x^{*}$ & $x^{*}$ \\
\hline
\end{tabular}

Note: $\checkmark$-successful and $x^{*}$-failed.

The second objective of this study was to assess the factors that may affect the ability of the NDTs used for leak detection. Therefore, to assess the effect of the varying factors, such as soil moisture content, pipe material, and types of leaks, on the leak detection potential of the NDTs, it was important to fix some other factors. Table 8 presents the effect of increasing soil moisture content on the potential of the leak detection of a given NDT. It was observed that the detection capability of the GPR and IR camera was significantly reduced when the moisture content was 10\%. Additionally, Table 9 illustrates the effect of the pipe material on the leak detection capabilities of NDT. The pipe material did not affect the detection ability of the NDTs. Lastly, the GPR and spectrometer could not be used on the pipe with the faulty joint due to surface ponding (Table 10). Contrary to this, the IR camera could be used. However, the presence of water on the surface was an indication of leak. Between the other types of leaks, there was no effect observed on the leak detection capabilities.

Table 8. Effect of soil moisture content on leak detection.

\begin{tabular}{cccc}
\hline Soil Moisture Content & $\mathbf{2 \%}$ & $\mathbf{5 \%}$ & $\mathbf{1 0} \%$ \\
\hline GPR & $66.67 \%$ & $66.67 \%$ & $33.33 \%$ \\
\hline Spectrometer & $66.67 \%$ & $22.23 \%$ & $0.00 \%$ \\
\hline IR camera & $100 \%$ & $100 \%$ & $0.00 \%$ \\
\hline
\end{tabular}

Table 9. Effect of pipe material on leak detection.

\begin{tabular}{cccc}
\hline Pipe Material & PVC & PE & PPR \\
\hline GPR & $55.56 \%$ & $55.56 \%$ & $55.56 \%$ \\
\hline Spectrometer & $33.33 \%$ & $22.22 \%$ & $33.33 \%$ \\
\hline IR camera & $66.67 \%$ & $66.67 \%$ & $66.67 \%$ \\
\hline
\end{tabular}

Table 10. Effect of types of leaks on leak detection.

\begin{tabular}{cccc}
\hline Types of Leaks & Crack & Hole & Faulty Joint \\
\hline GPR & $77.78 \%$ & $88.89 \%$ & $0 \%$ \\
\hline Spectrometer & $44.44 \%$ & $44.44 \%$ & $0 \%$ \\
\hline IR camera & $66.67 \%$ & $66.67 \%$ & $66.67 \%$ \\
\hline
\end{tabular}




\section{Conclusions}

From the results obtained above, the following conclusions can be made.

1. GPR: The GPR is effective in detecting leaks in sand/soil with a moisture content of $2-5 \%$. The detection of leaks using the GPR was effective when the moisture content of the sand surrounding the pipes was $2 \%$. Furthermore, although the GPR was able to detect leaks when the moisture content of the sand was $5 \%$, the visual inspection of the GPR scans required special attention to details as the sand was already moisty. Contrary to this, the GPR was not able to effectively detect leaks when the moisture content was approximately $10 \%$. In addition, the GPR was able to detect leaks in all pipe materials.

2. Spectrometer: The spectrometer used in this study was able to detect leaks in all three types of pipes (PE, PPR and PVC) at $2 \%$ moisture content. However, the results did not follow a constant trend and identifying the leak was tricky. As the moisture content approached 5\%, the spectrometer was only able to identify the leak in two cases, which were the PVC pipe with a crack and PPR pipe with a hole. Hence, it can be concluded that this spectrometer (spectral range of $0.20-0.85 \mu \mathrm{m}$ ) with its limited infrared spectral range cannot be deemed as an effective NDT to detect leaks in pipes when the moisture content is $5 \%$ or higher. Based on the results obtained from the IR camera, it is suggested that spectrometers with wider infrared ranges would be successful in detecting such leaks.

3. IR camera: The IR camera (spectral range: 7.5-13.0 $\mu \mathrm{m}$ ) used in this study was effective in detecting leaks when the moisture content of the soil surrounding the pipes was approximately $2-5 \%$. Moreover, the IR camera can detect leaks in all three pipe materials (PE, PPR and PVC).

4. Effect of soil moisture content: The ability of the three chosen NDTs to detect water leaks decreases with the increase in the moisture content of the soil. Therefore, the NDTs are only successful in capturing the significant increase in the soil moisture content due to the leaks.

5. Pipe material: There was no significant effect on the ability of the NDTs to detect water leaks when the material of the pipe was PE, PPR, or PVC. Hence, if there is leak in any of the three types of pipes used in this study, it can be detected by means of the tested NDTs.

6. Types of leaks: The tested NDTs were able to successfully detect the leaks due to a crack or hole in a pipe. However, the GPR was inefficient in detecting leaks from the faulty joint due to the surface ponding.

In summary, out of the three instruments used in the present research study, the IR camera was the most effective in identifying the leaks. The spectrometer, however, given its limited spectral range, was the least reliable NDT to detect leaks. In addition to this, the NDTs were more effective when the moisture content of the sand surrounding the pipes was low $(2-5 \%)$. This research will be a significant step towards building a comprehensive knowledge related to the use of NDTs for water leak detection, as comprehensive studies on water leak detection are lacking in literature. Existing knowledge is often limited to the applicability of the individual technologies. The effect of different factors on the use of these NDTs will be a major contribution for this paper as it will ensure the versatility of these technologies. However, the outcomes of this study may not always represent the real-site conditions. The experimental setup used in this study was controlled and scaled. It reduced the potential interferences from other weather and soil environments. However, in real situations, the lack of boundary walls in the vicinity may reduce the efficiency of the NDTs slightly. The extent of that impact was outside the scope of this study.

Future studies should aim to focus on the applicability of these technologies in the realsite conditions under varying operational, atmospheric, and weather conditions. This is particularly essential for all the manufacturers of NDTs. Since wide-ranging NDTs are being 
introduced for leak detection, it is essential that the academics, practitioners, and policymakers evaluate the role of different factors in ensuring the efficiency of leak detection.

Author Contributions: Conceptualization, M.M.M., S.Y. and T.A.; software, H.A., M.K.; validation, S.Y., T.A. and M.M.M.; formal analysis, H.A. and M.K.; investigation, M.M.M., S.Y. and T.A.; resources, M.M.M.; data curation, S.Y. and T.A.; writing—original draft preparation, H.A.; writing—review and editing, M.M.M., S.Y. and T.A.; visualization, M.M.M.; supervision, M.M.M., S.Y. and T.A.; project administration, M.M.M.; funding acquisition, M.M.M. All authors have read and agreed to the published version of the manuscript.

Funding: This research was funded by American University of Sharjah, grant number FRG16-R-29 and SCRI-18-08 and Sharjah Research Academy, SRA20-18 and the work in this paper was supported, in part, by the open access program (OAPCEN-1410-E00047) and professional development grant from American University of Sharjah. However, this paper represents the opinions of the authors and does not mean to represent the position or opinions of the American University of Sharjah.

Institutional Review Board Statement: Not applicable.

Informed Consent Statement: Not applicable.

Data Availability Statement: Some or all data, models, or codes that support the findings of this study are available from the corresponding author upon reasonable request. Unprocessed raw images originated from the experiments using different types of devices are available for this purpose.

Acknowledgments: The authors would like to thank the American University of Sharjah for providing the facilities and materials for this research study. In addition, the authors would like to acknowledge the help and contributions from several undergraduate students (Sneha Sasi, Pubudu Karunagoda, Mohiuddin Quadri, Amina Hammodat, Moutz Slim, and Mariam Nabulsi).

Conflicts of Interest: The authors declare no conflict of interests.

\section{References}

1. Lambert, A. Assessing non-revenue water and its components: A practical approach. Water 2003, 21, 50-51.

2. Puust, R.; Kapelan, Z.; Savic, D.A.; Koppel, T. A review of methods for leakage management in pipe networks. Urban Water J. 2010, 7, 25-45. [CrossRef]

3. Dubai Electricity and Water Authority. DEWA Sustainability Report 2015; DEWA: Dubai, United Arab Emirates, 2016.

4. Cabrera, E. Pumps, Electromechanical Devices and Systems Applied to Urban Water Management; Taylor \& Francis: Abingdon, UK, 2003.

5. Mortula, M.M.; Fattah, K.P.; Ali, T.A.; Idris, A.; Bardan, M. Spatiotemporal assessment of water quality in the distribution network of City of Sharjah, UAE. Int. J. Inf. Decis. Sci. 2019, 11, 116-128. [CrossRef]

6. United Nations. Goal 6: Ensure Availability and Sustainable Management of Water and Sanitation for All. Available online: https://sdgs.un.org/goals/goal6 (accessed on 23 December 2021).

7. Liu, Z.; Kleiner, Y. State of the art review of inspection technologies for condition assessment of water pipes. Measurement 2013, 46, 1-15. [CrossRef]

8. Xu, X.; Karney, B. An overview of transient fault detection techniques. In Modeling and Monitoring of Pipelines and Networks; Verde, C., Torres, L., Eds.; Springer: Berlin/Heidelberg, Germany, 2017; pp. 13-37.

9. Meniconi, S.; Capponi, C.; Frisinghelli, M.; Brunone, B. Leak detection in a real transmission main through transient tests: Deeds and misdeeds. Water Resour. Res. 2021, 57, e2020WR027838. [CrossRef]

10. Brunone, B.; Capponi, C.; Meniconi, S. Design criteria and performance analysis of a smart portable device for leak detection in water transmission mains. Measurement 2021, 183, 109844. [CrossRef]

11. Gizzi, F.T.; Leucci, G. Global Research Patterns on Ground Penetrating Radar (GPR). Surv. Geophys. 2018, 39, 1039-1068. [CrossRef]

12. Ayala-Cabrera, D.; Campbell, E.; Carreño-Alvarado, E.P.; Izquierdo, J.; Pérez-García, R. Water Leakage Evolution Based on GPR Interpretations. Procedia Eng. 2014, 89, 304-310. [CrossRef]

13. Lai, W.W.L.; Chang, R.K.W.; Sham, J.F.C.; Pang, K. Perturbation mapping of water leak in buried water pipes via laboratory validation experiments with high-frequency ground penetrating radar (GPR). Tunn. Undergr. Space Technol. 2016, 52, 157-167. [CrossRef]

14. De Coster, A.; Medina, J.L.P.; Nottebaere, M.; Alkhalifeh, K.; Neyt, X.; Vanderdonckt, J.; Lambot, S. Towards an improvement of GPR-based detection of pipes and leaks in water distribution networks. J. Appl. Geophy. 2019, 162, 138-151. [CrossRef]

15. Zajícová, K.; Chuman, T. Application of ground penetrating radar methods in soil studies: A review. Geoderma 2019, 343, 116-129. [CrossRef] 
16. Hadjimitsis, D.G.; Agapiou, A.; Themistocleous, K. Integrated Use of Space, Geophysical and Hyperspectral Technologies Intended for Monitoring Water Leakages in Water Supply Networks; IntechOpen: London, UK, 2014.

17. Stampolidis, A.; Soupios, P.; Vallianatos, F.; Tsokas, G.N. Detection of leaks in buried plastic water distribution pipes in urban places-A case study. In Proceedings of the 2nd International Workshop on Advanced Ground Penetrating Radar, Delft, Netherlands, 14-16 May 2003; pp. 120-124. [CrossRef]

18. Eyuboglu, S.; Mahdi, H.; Al-Shukri, H. Detection of water leaks using ground penetrating radar. In Proceedings of the 3rd International Conference on Applied Geophysics, Orlando, FL, USA, 8-12 December 2003.

19. Ayala-Cabrera, D.; Herrera, M.; Izquierdo, J.; Ocaña-Levario, S.J.; Pérez-García, R. GPR-Based Water Leak Models in Water Distribution Systems. Sensors 2013, 13, 15912-15936. [CrossRef]

20. Cataldo, A.; Persico, R.; Leucci, G.; De Benedetto, E.; Cannazza, G.; Matera, L.; De Giorgi, L. Time domain reflectometry, ground penetrating radar and electrical resistivity tomography: A comparative analysis of alternative approaches for leak detection in underground pipes. NDT E Int. 2014, 62, 14-28. [CrossRef]

21. Demirci, S.; Yigit, E.; Eskidemir, I.H.; Ozdemir, C. Ground penetrating radar imaging of water leaks from buried pipes based on back-projection method. NDT E Int. 2012, 47, 35-42. [CrossRef]

22. Nakhkash, M.; Mahmood-Zadeh, M.R. Water leak detection using ground penetrating radar. In Proceedings of the Tenth International Conference on Grounds Penetrating Radar, Delft, Netherlands, 21-24 June 2004; pp. 525-528.

23. Hunaidi, O.; Chu, W.; Wang, A.; Guan, W. Detecting leaks in plastic pipes. J. Am. Water Work. Assoc. 2000, 92, 82-94. [CrossRef]

24. Kuo, S.S.; Zhao, L.; Mahgoub, H.S.; Suarez, P.F. Investigation of Ground Penetrating Radar for Detection of Leaking Pipelines under Roadway Pavements and Development of Fiber-Wrapping Repair Technique; University of Central Florida: Orlando, FL, USA, 2005. Available online: https:/ / trid.trb.org/view.aspx?id=758052 (accessed on 29 June 2018).

25. Topp, G.C.; Davis, J.L.; Annan, A.P. Electromagnetic determination of soil water content: Measurements in coaxial transmission lines. Water Resour. Res. 1980, 16, 574-582. [CrossRef]

26. Mortula, M.; Aslam, H.; Karunagoda, P.; Quadri, S.; Slim, M.; Hammodat, A.; Al Nabulsi, M.; Ali, T. Use of Spectrometer for Detection of Leaks in Water Distribution System. In Proceedings of the 1st International WDSA/CCWI Joint Conference, Kingston, ON, Canada, 23-25 July 2018.

27. Aslam, H.; Kaur, M.; Sasi, S.; Mortula, M.; Yehia, S.; Ali, T. A Conceptual Approach to Detection of Water Pipe Leakage using Non-Destructive Techniques. In Proceedings of the International Conference on Water, Energy and Environment, Sharjah, United Arab Emirates, 28 February-2 March 2017.

28. Aslam, H.; Kaur, M.; Sasi, S.; Mortula, M.M.; Yehia, S.; Ali, T. Detection of Leaks in Water Distribution System using NonDestructive Techniques. IOP Conf. Ser. Earth Environ. Sci. 2018, 150, 012004. [CrossRef]

29. Younis, S.M.Z.; Iqbal, J. Estimation of soil moisture using multispectral and FTIR techniques. Egypt. J. Remote Sens. Space Sci. 2015, 18, 151-161. [CrossRef]

30. Demattê, J.A.M.; Sousa, A.A.; Alves, M.C.; Nanni, M.R.; Fiorio, P.R.; Campos, R.C. Determining soil water status and other soil characteristics by spectral proximal sensing. Geoderma 2006, 135, 179-195. [CrossRef]

31. Tian, J.; Philpot, W.D. Relationship between surface soil water content, evaporation rate, and water absorption band depths in SWIR reflectance spectra. Remote Sens. Environ. 2015, 169, 280-289. [CrossRef]

32. Roosjen, P.P.J.; Bartholomeus, H.M.; Clevers, J.G.P.W. Effects of soil moisture content on reflectance anisotropy-Laboratory goniometer measurements and RPV model inversions. Remote Sens. Environ. 2015, 170, 229-238. [CrossRef]

33. Weidong, L.; Baret, F.; Xingfa, G.; Qingxi, T.; Lanfen, Z.; Bing, Z. Relating soil surface moisture to reflectance. Remote Sens. Environ. 2002, 81, 238-246. [CrossRef]

34. Nocita, M.; Stevens, A.; Noon, C.; van Wesemael, B. Prediction of soil organic carbon for different levels of soil moisture using Vis-NIR spectroscopy. Geoderma 2013, 199, 37-42. [CrossRef]

35. Fabre, S.; Briottet, X.; Lesaignoux, A. Estimation of Soil Moisture Content from the Spectral Reflectance of Bare Soils in the 0.4-2.5 $\mu \mathrm{m}$ Domain. Sensors 2015, 15, 3262-3281. [CrossRef] [PubMed]

36. Lobell, D.B.; Asner, G.P. Moisture Effects on Soil Reflectance. Soil Sci. Soc. Am. J. 2002, 66, 722-727. [CrossRef]

37. Fahmy, M.; Moselhi, O. Automated Detection and Location of Leaks in Water Mains Using Infrared Photography. J. Perform. Constr. Facil. 2010, 24, 242-248. [CrossRef]

38. Atef, A.; Zayed, T.; Hawari, A.; Khader, M.; Moselhi, O. Multi-tier method using infrared photography and GPR to detect and locate water leaks. Autom. Constr. 2016, 61, 162-170. [CrossRef]

39. Awwad, A.; Yahya, M.; Albasha, L.; Mortula, M.M.; Ali, T. Remote Thermal Water Leakage Sensor with a Laser Communication System. IEEE Access 2020, 8, 163784-163796. [CrossRef]

40. Shakmak, B.; Al-Habaibeh, A. Detection of water leakage in buried pipes using infrared technology; A comparative study of using high and low resolution infrared cameras for evaluating distant remote detection. In Proceedings of the 2015 IEEE Jordan Conference on Applied Electrical Engineering and Computing Technologies (AEECT), Amman, Jordan, 3-5 November 2015; pp. 1-7. [CrossRef]

41. Eidenshink, J.C. Detection of leaks in buried rural water pipelines using thermal infrared images. Photogramm. Eng. Remote Sens. 1985, 51, 561-564.

42. El-Zahab, S.; Zayed, T. Leak detection in water distribution networks: An introductory overview. Smart Water 2019, 4, 5. [CrossRef] 
43. Wazlan, W.S. Assessing the Condition of Buried Pipe Using Ground Penetrating Radar. Ph.D. Thesis, The University of Birmingham, Birmingham, UK, 2014. Available online: https:/ / etheses.bham.ac.uk/id/eprint/4772/ (accessed on 29 June 2019).

44. GSSI. Concrete Handbook; Geophysical Survey Systems, Inc.: Nashua, NH, USA, 2017.

45. Fattah, K.P.; Mortula, M. Leaching of organic material in polymeric pipes distributing desalinated water. Int. J. Hydrol. Sci. Technol. 2020, 10, 210-219. [CrossRef]

46. Ercoli, M.; Di Matteo, L.; Pauselli, C.; Mancinelli, P.; Frapiccini, S.; Talegalli, L.; Cannata, A. Integrated GPR and laboratory water content measures of sandy soils: From laboratory to field scale. Constr. Build. Mater. 2018, 159, 734-744. [CrossRef]

47. Yehia, S.; Abudayyeh, O.; Nabulsi, S.; Abdelqader, I.; Siddagangappa, J. GPR Imaging Evaluation of the Napier Avenue Interchange on I-94 Culvert. In Proceedings of the ASCE International Conference on Computing in Civil Engineering, Cancun, Mexico, 12-15 July 2005; pp. 1-7. [CrossRef]

48. Yehia, S.; Abudayyeh, O.; Nabulsi, S.; Abdelqader, I. Detection of Common Defects in Concrete Bridge Decks Using Nondestructive Evaluation Techniques. J. Bridge Eng. 2007, 12, 215-225. [CrossRef]

49. Yehia, S. GPR an Effective Tool inside the Inspector's Toolbox. In Proceedings of the 2nd Conference on Service Life Design for Infrastructure, Delft, The Netherlands, 4-6 October 2010.

50. Yehia, S.; Qaddoumi, N.; Farrag, S.; Hamzeh, L. Investigation of concrete mix variations and environmental conditions on defect detection ability using GPR. NDT E Int. 2014, 65, 35-46. [CrossRef] 